\title{
Developing a Practical Consumable Reinforcer for the Experimental Analysis of Human Operant Behavior
}

\author{
Emily Hill Morris \\ West Virginia University
}

Follow this and additional works at: https://researchrepository.wvu.edu/etd

\section{Recommended Citation}

Hill Morris, Emily, "Developing a Practical Consumable Reinforcer for the Experimental Analysis of Human Operant Behavior" (2012). Graduate Theses, Dissertations, and Problem Reports. 3499.

https://researchrepository.wvu.edu/etd/3499

This Thesis is protected by copyright and/or related rights. It has been brought to you by the The Research Repository @ WVU with permission from the rights-holder(s). You are free to use this Thesis in any way that is permitted by the copyright and related rights legislation that applies to your use. For other uses you must obtain permission from the rights-holder(s) directly, unless additional rights are indicated by a Creative Commons license in the record and/ or on the work itself. This Thesis has been accepted for inclusion in WVU Graduate Theses, Dissertations, and Problem Reports collection by an authorized administrator of The Research Repository @ WVU. For more information, please contact researchrepository@mail.wvu.edu. 
Developing a Practical Consumable Reinforcer

for the Experimental Analysis of Human Operant Behavior

\author{
Thesis submitted to the \\ Eberly College of Arts and Sciences \\ at West Virginia University \\ in partial fulfillment of the requirements \\ for the degree of \\ Master of Science in Psychology \\ Michael Perone, Ph.D., Chair \\ Elizabeth Kyonka, Ph.D. \\ Constance Toffle, Ph.D.
}

Department of Psychology

Morgantown, West Virginia

2012

Keywords: Human operant, Task Effort, Schedules of Reinforcement

Copyright 2012 Emily A. Hill 


\author{
ABSTRACT \\ Developing a Practical Consumable Reinforcer for the \\ Experimental Analysis of Human Operant Behavior \\ Emily Hill Morris
}

Two projects tested the reinforcing efficacy of a reduction in effort associated with a computerbased laboratory task. In both projects, college students could earn points exchangeable for money by working on an Imposed task or, by executing a changeover response, they could earn the points on an Alternate task. Of interest was whether access to the Alternate task would reinforce the changeover response. In Project 1 the students tracked a moving target on the screen. In the Imposed task the target was programmed to move faster and change directions more frequently relative to the target in the Alternate task. Despite several manipulations of the task parameters, changeover responding failed to occur reliably. In Project 2 the students copied a string of words that appeared on the screen. In the Imposed task the characters of the words were garbled such that they appeared nonsensical to the student. The words in the Alternate task were written in English and followed a comprehensive storyline. During this project changeover responding was reliably maintained. Developing an effective yet practical method of reinforcing human operant behavior in laboratory experiments remains a challenge. 


\section{Acknowledgements}

I would like to thank Michael Perone, Elizabeth Kyonka, and Constance Toffle for serving on my thesis committee. I appreciate both their time and input in completing my project.

I would like to extend special thanks to Mike for his support and guidance throughout the course of this project. I have learned so much by working with him. 


\section{Table of Contents}






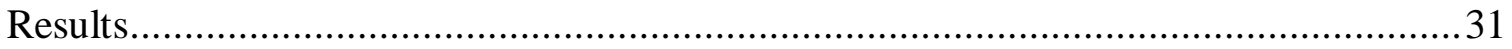



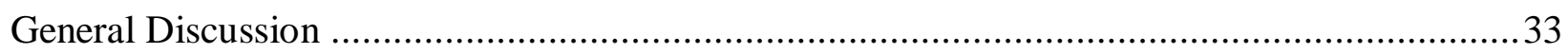

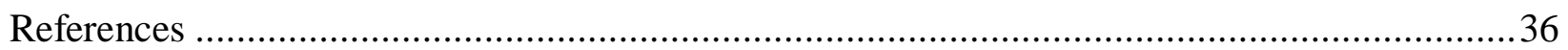




\section{List of Tables}

Table 1. Key issues to be addressed between points or money (typically used in human operant studies) and food (typically used in animal studies) as reinforcers

Table 2. Parameters of target behavior: Velocity and rate of spontaneous changes in direction. 39

Table 3. Session by session data for Student 1 in Project 1 . The abbreviation MULT is used for sessions where a multiple schedule was in place. Only data collected during the Imposed task is displayed. Lines separate phase changes

Table 4. Session by session data for Student 2 in Project 1. The abbreviation MULT is used for sessions where a multiple schedule was in place. Only data collected during the Imposed task is displayed. Numbers listed under session earnings with parentheses around them are negative amounts. Lines separate phase changes

Table 5. Session by session data for Student 3 in Project 1. The abbreviation MULT is used for sessions where a multiple schedule was in place. Only data collected during the Imposed task is displayed. Lines separate changes in the postponement interval.

Table 6. Shows summary results for Students 4 and 5 in Project 2. Results are based on per session averages. Only sessions where a task was activated at least once were included in the calculation 


\section{List of Figures}

Figure 1. Original screen display for Project 1 when the Imposed task was activated. The left panel constitutes the Imposed task and the right panel constitutes the Alternate task. The rectangle below the left panel is the changeover button

Figure 2. Number of changeover responses per session for Student 1 in Project 1 .46

Figure 3. Revised screen display for Project 1 when the Imposed task was activated. The bar above the left task panel constitutes the progress bar for the point-loss postponement schedule. Instructions were also added to the changeover button

Figure 4. Number of changeover responses per session for Student 2 in Project 1

Figure 5. Number of changeover responses per session for Student 3 in Project 1. During Phase 1 the velocity and directional changes of the target were manipulated by adjusted the Imposed task level as displayed in Table 4. During Phase 2 the postponement interval was manipulated. The size of the interval is listed for the Imposed task first followed by the Alternate task and separated by a comma. Changes in the postponement interval are separated by a dotted line.....49

Figure 6. Shows the screen display for Project 2 when the Imposed task is activated and the Esc key is unavailable. The bottom, light blue panel, where the string of words is garbled, is the Imposed task. The top, light yellow panel is the Alternate task.....

Figure 7. Screen display for the fixed-ratio and reversal phases of Project 2 when the Garbled Task was activated and the Esc key was available..

Figure 8. shows the initial screen display during the multiple schedule.

Figure 9. Shows the screen display when students could activate either the Alternate or the Imposed task by pressing the Up-arrow or Down-arrow key respectively...

Figure 10. Mean post-reinforcement pause per session for Student 5 in Project 2. Sessions where a ratio run was never completed were excluded from the graph..

Figure 11. Mean post-reinforcement pause per session for Student 2 in Project 2. Sessions where a ratio run was never completed were excluded from the graph. 
Figure 12. Number of changeover responses per session during the reversal phase of Project 2

for Student 4. Phases are designated by type of transcription that served as the Imposed task ....56

Figure 13. Number of changeover responses per session during the reversal phase of Project 2 for Student 5. Phases are designated by the type of transcription that served as the Imposed task. 57 
The experimental analysis of behavior is based on the assumption that the same basic principles govern the behavior of humans and nonhumans (hereafter referred to as animals.) The literature on human operant behavior, however, seems to provide evidence to the contrary. When structurally similar schedules of reinforcement have been arranged for humans and animals, the resulting performances have sometimes been different. For instance, fixed-interval (FI) schedules of reinforcement typically produce a distinct "scalloped" pattern of responding in animals which is characterized by a pause after the delivery of a reinforcer followed by a gradual increase in responding until the delivery of the next reinforcer (Ferster \& Skinner, 1957). Lowe and Harzem (1977) argued that when FI schedules are arranged with human subjects they tend to produce either high-rate steady responding, where the subject will continue to respond throughout the interval, or low-rate responding, where the subject will respond only a few times usually near the end of the interval

Behavior analysts have reacted to inconsistent results such as these in two general ways. First, some have concluded that the discrepancies are due to fundamental differences in the principles that govern human and animal behavior (Brewer, 1974). For example, Lowe (1979) suggested that human behavior is mediated by a person's thoughts, beliefs, and hypotheses about their environments which affect the influence of experimental contingencies (for a review see Perone, Galizio, \& Baron 1991). By this reckoning, animal and human research should proceed independently from one another.

The second reaction to the human-animal discrepancies is to attribute them to methodological problems. Madden and Perone (1999), among others, argued that procedural differences rather than behavioral differences account for the variance between humans and animals in producing 
sensitivity to programmed contingencies. By this reckoning, before we can make any conclusions about the applicability of animal-based principles to understanding human affairs, we must first attempt to remedy procedural differences.

Kollins, Newland, and Critchfield (1997) suggested that human-animal differences may not indicate fundamental differences between species but rather a failure to control the critical variables. They argued that schedule-sensitive behavior depends on selecting an appropriate reinforcer and arranging experimental operations that establish the effectiveness of the reinforcer. These two factors, reinforcers and their underlying establishing operations, constitute the focus of the proposed research.

The differences between animal and human studies in selecting reinforcers and arranging experimental contingencies have methodological and theoretical implications (see Galizio \& Buskist, 1988). Whereas the procedures used in animal and human studies may be structurally similar, they may be functionally different. For example, the conventional reinforcer used in animal studies is food whereas points or points exchangeable for money are more typical in human studies. Points may be practical and easy to implement, but it is unclear if they are functionally equivalent to food in controlling human behavior.

Table 1 outlines three important differences between points and food as reinforcers. The first difference concerns whether or not we can be sure that the subject has contacted the reinforcer at the time of delivery. In animal studies that use food as a reinforcer, the animal will stop responding on the schedule to consume the food when it is delivered. This consumatory behavior competes with responding on the schedule in effect. In human operant procedures that use points or money, subjects do not necessarily come into direct contact with the reinforcer at the time of delivery. For example, a running tally of earned points may be kept in a box on the computer 
screen, but the procedure may not require that the subject stop responding to observe the accumulation of points. In such a case, it cannot be confirmed that the subject has contacted the reinforcer at the moment of delivery or, for that matter, at any point during the session. The second difference concerns when the reinforcer is consumed by the subject. Food is consumed at the moment of delivery, whereas points have no immediate significance to the subject. Often the subject must wait until the experiment is over to exchange their points for money or other tangible reinforcers. In either case, the money cannot be spent and the tangible reinforcer cannot be contacted until well after the schedule-controlled delivery of the reinforcer during the session.

The third difference concerns whether or not the operations that establish the experimental event as a reinforcer are controlled by the experimenter. An establishing operation is any operation that changes the status of a stimulus as a reinforcer or punisher (Catania, 1998). The efficacy of food as a reinforcer can be manipulated, to an extent, by the experimenter through levels of deprivation (Galizio \& Buskist, 1988). By depriving the animal of food beforehand, the experimenter ensures that food will function as a reinforcer. We cannot control as efficiently the operations that establish points or money as a reinforcer for humans. We cannot, for example, manipulate the subject's economic status to establish the reinforcing function of a quarter. The reinforcing value of points and money is unclear in that it depends on the subject's experience outside of the experiment.

Researchers, of course, have addressed these issues in a number of ways. Matthews, Shimhoff, and Catania (1977), addressed the first issue by stressing the importance of implementing a consumatory response that is structurally similar to eating food in animal studies. By requiring a separate response that interrupted the subject's responding on the schedule in effect, researchers 
could ensure that the subject had contacted the reinforcer at the time of delivery. In their study, students' responses on a telegraph key were reinforced on either a variable-ratio (VR) or variable-interval (VI) schedule with points exchangeable for money. To collect each reinforcer as it was scheduled, students had to press a separate button - this was intended as an analog of the conventional consumatory behavior associated with food reinforcement. Matthews et. al. found that when the procedure was arranged in this way, human subjects showed sensitivity to the reinforcement schedule in effect: Response rates were higher on the VR schedule than on the VI schedule. This difference is typical of animal studies that use the same schedules. Although Matthews et al. addressed Issue 1, they only partly addressed issue 2 and did not address issue 3 . Although their analog-consumatory response ensured that the subject contacted the points when they were delivered (Issue 1), the fact remains that the points were not consumed during the session (Issue 2). In addition the experimenters did not demonstrate control over the efficacy of the reinforcer (Issue 3).

Navarick (1982) used the offset of white noise as a reinforcer in a study on impulsivity and selfcontrol. Subjects could turn off the noise by pressing one of two buttons, each associated with a different schedule of reinforcement. Navarick found that (a) subjects preferred immediate rather than delayed noise offset when the duration of the reinforcer was held constant; (b) subjects preferred a longer offset over a shorter offset when both were delivered immediately; and (c) preference for a short, immediate period of noise offset increased as a delay to a longer offset was raised. This shift in preference is an indication of impulsivity and often demonstrated with animal subjects. Offset of the noise was contacted by the subject at the time of delivery (Issue 1) and was immediately consumed (Issue 2). With regard the Issue 3, however, there are ethical limitations on the extent to which an experimenter can control the establishing operations 
involving a stimulus, such as noise, that may create physical damage at intense levels. This restricts the extent to which these procedures can be explored and compared to animal counterparts.

By using cigarette smoke as a reinforcer in a study of behavioral economics, Bickel, Degrandpre, Hughes, \& Higgins (1991) demonstrated a way to address all three of the issues outlined in Table 1. In this study pulls on a plunger were reinforced on a fixed-ratio (FR) schedule with puffs of smoke. Both the ratio requirement and the number of puffs delivered were manipulated. Upon completion of the response requirement, subjects were instructed to inhale a specific number of puffs based on a uniform-puff procedure. This involved inhaling, holding the smoke in the lungs for $5 \mathrm{~s}$ and exhaling. Subjects were given 5 min to consume all puffs earned between trials during which time any additional responses on the plunger would not be reinforced. Smoking disrupted responding on the plunger ensuring that the subject made contact with the reinforcer at the time of delivery (Issue 1). Puffs of cigarettes were consumed in the moment (Issue 2), and the experimenter demonstrated control over the establishing operations of the reinforcer by requiring subjects to abstain from smoking for 5 to $6 \mathrm{hr}$ before a session (Issue 3). The problem with procedures such as this is that they can be complicated to implement. Studies that use cigarette smoke or other addictive reinforcers such as alcohol or drugs often require specialized equipment and laboratory settings which many researchers may not be able to arrange. In addition, these studies may require that the Students have specific pre-existing characteristics, such as an addiction to nicotine, which limits the number of potential students. As such, these types of studies are not practical to use in conventional academic psychological laboratories. A promising method of addressing the issues in Table 1 can be found in a study reported by Miller (1968). The subject was given a choice of two tasks in which they pulled a plunger to 
earn coins or cigarettes on a VI schedule. During the Imposed Task, the plunger required $20 \mathrm{lb}$ of force to operate. By emitting a vocal response, the subject could change over from the Imposed Task to an Alternate Task for $60 \mathrm{~s}$ during which the plunger required only $1 \mathrm{lb}$ of force to operate. Changeover responding was conditioned and maintained by presentation of the Alternate Task.

In subsequent conditions, both the Imposed force requirement and the schedule arranging access to the Alternate Task were manipulated. Miller (1968) found that the rate of changeover responding was a function of the force requirement in the Imposed Task. That is, as the force requirement increased, the rate of changeover responding also increased. When the Imposed force requirement was $1 \mathrm{lb}$ - the same as in the Alternate Task - changeover responding extinguished. Miller also found that when the Alternate Task was arranged on a FR schedule, subjects showed break and run patterns of responding. This consisted of a pause in responding between the end of the Alternate Task and the next changeover response. The duration of the pause was a function of the ratio requirement. That is, as the ratio increased the duration of the pause also increased. This post-reinforcement pause is a common characteristic of response patterns in animal studies that use FR schedules. Because the Alternate Task functioned as a reinforcer that produced typical schedule control in human subjects, Miller's procedure holds promise as a method for the experimental analysis of human behavior. The reduction in task effort is a reinforcer that the subject contacts at the time of delivery (Issue 1) and is consumed in the moment (Issue 2). In addition, the operations that establish the value of the reinforcer can be manipulated by the experimenter (Issue 3) by adjusting the force requirement.

One goal of this study was to develop a method in which the opportunity to switch from a relatively difficult task to an easier task would function as a reinforcer. A second goal was to use 
apparatuses that are readily available to researchers in many different laboratories. To accomplish these goals, a systematic replication of Miller's study was conducted using a computer program to arrange the Imposed and Alternate tasks. If this method proved to be effective, it would provide opportunities to better compare schedule effects across human and animal subjects, because the conventional computer equipment required is readily available in academic psychology laboratories.

Two sets of the Imposed and Alternate tasks were developed. In Project 1, the Imposed and Alternate tasks involved tracking a moving target on the screen using a mouse cursor. The velocity and directional tendencies of the target were manipulated across sessions. In general, the target in the Imposed task was programmed to move faster and change directions more frequently relative to the target in the Alternate task.

In Project 2, the Imposed and Alternate tasks involved copying a string of words displayed on the computer screen using the computer keyboard. In the Imposed task the characters of the words were garbled such that they appeared nonsensical to the student. The words in the Alternate task were written in English and followed a story line.

\section{General Method}

\section{Students}

Five undergraduate students from West Virginia University were recruited from introductory psychology classes. All of the students were female and between 18 and 19 years of age. Students 1, 2, and 3 participated in Project 1. Students 4 and 5 participated in Project 2.

\section{Apparatus}

Each student worked individually in a small room (approximately $6 \mathrm{ft} \times 7 \mathrm{ft}$ ), seated at a table (60 in. $\mathrm{x} 30$ in.). On top of the table was a computer monitor with a screen measuring 
approximately 11.75 in. x 18.75 in. (a "wide screen" measuring 22 in. diagonally); the screen's resolution was $1280 \times 768$ pixels. Behind the monitor was a speaker connected to a white noise generator (Layfayette Model 15800). The noise helped to mask extraneous sounds from other areas of the laboratory. Below the table was a keyboard tray holding a computer mouse and, in Project 2, a keyboard. The volume of the noise and the height and tilt of the keyboard tray were adjusted for the individual comfort of each student. A computer in an adjacent room was used to arrange the experimental contingencies and collect data by way of software developed with the Express edition of Visual Basic 2008 in Project 1 and the Express edition of Visual Basic 2010 in Project 2.

\section{Procedure}

Sessions were 24 minutes in duration and were usually scheduled in pairs. Students were given the option to take a break at least every two sessions. No more than six sessions were scheduled in a single visit to the laboratory. At the onset of the first session, a demographic questionnaire appeared on the screen that included questions about gender, age, what psychology classes the student had taken, and whether their ability to see the screen was impaired in any way. In Project 2, students were also asked if they were touch typists (can type mostly without looking at the keyboard). Students gave informed consent by signing a contract to participate for as many as 60 hours, about 5 to 20 hours per week.

Monetary Schedules - Throughout the course of the study, students were able to earn points exchangeable for money. Payment was based on performance, with maximum earnings of about $\$ 6.25$ per hour. To discourage students from dropping out of the project, there was an additional bonus payment of $\$ 2.00$ per session, to be paid contingent upon completing all scheduled 
sessions. Payment was made at the end of each student's participation, but the student received a printed summary of the earnings to date at the end of every visit to the laboratory.

\section{Project 1}

The present research was exploratory in nature. As such, the progression of events in Project 1 took an unconventional path. Therefore, the report of the research is also unconventional. The procedures were modified frequently in response to session data. Details of the specific procedure used with each student are intertwined with the results for that student. In Project 1 students were able to earn points exchangeable for money by clicking a moving target. Two targets were available, one in the Imposed task and one in the Alternate task. Students could track only one target at a time. The purpose of Project 1 was to identify parameters of the Imposed task that would maintain a changeover response to the Alternate task. During most sessions, the target in the Imposed task was programmed to move faster and change directions more frequently relative to the target in the Alternate task. Project 1 was based on the assumption that switching from the Imposed to the Alternate task would represent a reduction in task effort. Based on the results of Miller's study it was expected that the presentation of the Alternate task would function as a reinforcer for conditioning and maintaining a changeover response.

\section{Tasks}

Figure 1 shows the original screen display for Project 1when the Imposed task was activated. The right panel (300 mm x $220 \mathrm{~mm}, \mathrm{H}$ x W) had black boundary lines with a light blue interior and constituted the Alternate task. The left panel (300 mm x $220 \mathrm{~mm}, \mathrm{H} \mathrm{x} \mathrm{W})$ had black boundary lines with a light yellow interior and constituted the Imposed task. Below the left task panel was a changeover button $(15 \mathrm{~mm}$ x $90 \mathrm{~mm})$, with a black outline and an interior color that 
matched that of the right panel (light blue). The active task was designated by a bar above the task panel; the bar $(8 \mathrm{~mm} \times 220 \mathrm{~mm})$ had a black outline and an interior color that matched the active task panel (light blue or yellow). The active task panel was displayed with full color intensity. When a task was inactive and inaccessible the color of the panel was faded.

Each task panel contained its own moving target. The target measured 7-mm square with a black outline and a black interior unless the target was clicked, when the interior briefly changed to white. The target moved at a 45-degree angle, that is, its vertical and horizontal coordinates changed at equal rates. If the target was moving upward to the left at a 45-degree angle, its direction could be described as "northwest;" if it was moving upward to the right, the direction was "northeast;" if it was moving downward to the left, the direction was "southwest;" and if it was moving downward to the right, the direction was "southeast." When the target reached any boundary of a panel, it changed direction, giving the impression of bouncing off the boundary. Points were delivered for clicking the targets either on a VI 30 s schedule or a VI 20 s schedule. The size of the schedule was determined by the experimenter before the onset of a session and the schedules were always equated between the Imposed and Alternate tasks. When a click satisfied the schedule in effect, the target froze in position, and a message box (approximately 50 $\mathrm{mm} \times 65 \mathrm{~mm}$ ) appeared in the center of the task panel. In black letters against a white background, the message read, "You scored! Click here to collect your point." After the student clicked the message box it disappeared and the target resumed its motion. To prevent lapses in target pursuit, a schedule of point-loss postponement was programmed conjointly with the VI schedule of point production. Students could avoid the loss of a point by clicking the computer mouse anywhere in the active task panel, on or off the target. The size of the postponement interval ranged between 1 and 4 seconds in the Imposed task and 2 and 4 
seconds in the Alternate task. The size of the postponement interval was determined by the experimenter for each task at the onset of each session. When a click occurred, the postponement interval was restarted from the beginning. If a click did not occur before the postponement interval elapsed, the target froze in position and a message box (approximately $50 \mathrm{~mm} \times 85 \mathrm{~mm}$ ) appeared in the center of the task panel. In white letters against a red background, the message read, "You lost a point. Click here to resume." After the student clicked the message box, the box disappeared, the target resumed its motion, and the postponement interval was restarted. Depending on the experimental condition, two aspects of the target's behavior were manipulated. First, the velocity of the target could range from $11 \mathrm{~mm}$ per second to $67 \mathrm{~mm}$ per s. Second, the number of spontaneous direction changes made (changes in direction that occurred without reaching a boundary line) could either be 15 or 30 per minute. Table 2 outlines the eight possible combinations of the velocity and directional tendencies of the target. These combinations constitute the eight levels of difficulty for the Imposed task.

When the session began, the Imposed task was activated. The mouse cursor was confined to the active task panel (and, in some cases, the area directly below it). Each task was associated with an independent set of point-production and point-loss postponement schedules. These schedules were suspended when a task was inactive and inaccessible.

By clicking the changeover button, the students could switch from the Imposed task to the Alternate task for either $60 \mathrm{~s}$ or $120 \mathrm{~s}$. The duration of the Alternate task was determined by the experimenter before the onset of a session. A progress bar measuring $4 \mathrm{~mm}$ x $85 \mathrm{~mm}$, also with a black outline and light blue interior was displayed directly above the button. When the student clicked the button, the interior of the progress bar briefly changed to black, the Imposed task was deactivated and the Alternate task was activated. Once the Alternate task was activated, the 
button and its progress bar became unavailable and disappeared from the screen, the active task bar appeared above the Alternate task panel, the color of the Imposed task was faded, and the color of the Alternate task was shown in full intensity.

For two of the three students the level of the Imposed task was initially set to 3 as shown in Table 2 (velocity $=34 \mathrm{~mm} / \mathrm{s}, 30$ direction changes per min). For Student 3, the Imposed task was initially set to Level 6 (velocity $=51 \mathrm{~mm} / \mathrm{s}, 30$ direction changes per min). If 10 consecutive changeover responses occurred with a mean latency greater than or equal to $12 \mathrm{~s}$, or if there was any individual latency greater than $120 \mathrm{~s}$, the level of the Imposed task was increased to the next highest level as listed in Table 2. The idea was to continue to raise the difficulty of the Imposed task until changeover responding was reliable. Changeover responding was considered reliable if 12 responses occurred in a single session when the Alternate task duration was $60 \mathrm{~s}$ or 6 responses in a single session when the Alternate task duration was 120 s. Since sessions were 24 minutes in duration, this acquisition criterion ensured that the student was spending at least half of their session time in the Alternate task.

At the start of every session, instructions appeared on the screen that read "You can earn points worth 6.7 cents (or 4.5 cents when the VI schedule was $20 \mathrm{~s}$ ) each by clicking on a moving target. You will learn more about the procedure as you work through it. Click the button when you are ready to start." A button with "Ready" written on it was located directly below the instructions. Once the student clicked the button the instructions disappeared and the session began.

Each student was exposed to the parameters of the Imposed and Alternate Task in the first session using a multiple schedule design. During this session each task was activated in an 
alternating sequence and remained active until the student earned six points, approximately three minutes. Each task was activated three times.

\section{Student 1}

Table 3 summarizes the experimental conditions of every session for Student 1 including the level of the Imposed task, the size of the VI schedule and postponement intervals in each task, and the total time spent in the Imposed task. In addition, Table 3 includes summary information on the number of points gained and lost, total session earnings, maximum possible session earnings, and number of clicks on-target, off-target, and near-target with an accuracy measure for the Imposed task.

Phase 1 - At the onset of the first session the difficulty of the Imposed task was set to Level 3 (velocity $=34 \mathrm{~mm} / \mathrm{s}, 30$ direction changes per $\mathrm{min}$ ), the VI schedule of point production was 30 $\mathrm{s}$, the duration of the Alternate task was $60 \mathrm{~s}$, and the postponement interval was $4 \mathrm{~s}$ in both tasks. During Session 1, the multiple schedule was in place. At the onset of Session 2, the changeover button became available. To expose the student to the new contingency, if $60 \mathrm{~s}$ passed from the start of the session without an initial response on the changeover button, then the target froze in place until a response occurred. After the target froze, however, Student 1 never made a changeover response. At one point she exited the room and asked if the program was broken; she was assured by the experimenter that everything was working properly. The session timed out after 24 min. As indicated in Table 3, Student 1 earned no points during this session. For this reason, instructions were added to the button in Session 3 that read "Click here." After Student 1 made an initial response, the Imposed task was deactivated and the Alternate task was activated for $60 \mathrm{~s}$. At the end of $60 \mathrm{~s}$ the student was transferred back to the Imposed task and the button became freely available. The target did not freeze again. 
Figure 2 shows the number of changeover responses per session for Student 1. Changeover responses for sessions that had a multiple schedule in place were not included since these sessions required a minimum number of changeover responses to occur. Since Student 1 did not press the changeover button frequently, the difficulty of the Imposed task was quickly raised such that by the end of Session 4, it had reached its terminal Level, 8 (Velocity $=67 \mathrm{~mm} / \mathrm{s}, 30$ direction changes per min). Since the difficulty of the Imposed task was adjusted automatically by the computer program, it is possible that changes in task parameters occurred before the student became sensitive to the contingencies in effect. For this reason, the difficulty of the Imposed task was reset to 5 (Velocity $=51 \mathrm{~mm} / \mathrm{s}, 15$ direction changes per min) in Session 5 in order to provide the student with additional exposure to the task parameters. Changeover responding was still occurring at a low rate and by the end of the session the Imposed level was back to 8 . Changeover responding continued at a low rate in Sessions 6 through 8 . Phase 2 - The purpose of Phase 2 was to increase sensitivity to the contingencies by manipulating the reinforcer magnitude and the rate of point production. As shown in Table 3 , in Session 9 the duration of the Alternate task was raised from $60 \mathrm{~s}$ to $120 \mathrm{~s}$ and the VI schedule was lowered from $30 \mathrm{~s}$ to $20 \mathrm{~s}$. This change meant that Student 1 would contact point delivery more often in both tasks. In addition, the instructions presented at the start of a session were changed to "You can earn points worth 6.7 cents each by clicking on 2 kinds of moving targets. Sometimes you will be able to choose which kind of target to click. You will learn more about the procedure as you work through it. Click the button when you are ready to start." The text in bold is what was added to the original instructions. The instructions were changed in order to make it more obvious to the student that they had a choice of which target they could track. At 
the onset of Session 9, the level of the Imposed task was reset to 3 and a multiple schedule was used to expose Student 1 to the new parameters.

Table 3 shows that by the end of Session 10 the Imposed level was back to 8 . As shown in Figure 2, changing the reinforcer magnitude and rate of point production did not result in an increase in changeover responding. For Phase 2, no more than 4 changeover responses occurred in a single session.

Phase 3 - Figure 3 shows a revised screen display when the Imposed task was activated. A progress bar was added to increase sensitivity to the point-loss contingency. The progress bar had a black boarder with a yellow interior and was designed to show how much time remained before a point deduction would occur. If, for example, the postponement interval was set to $4 \mathrm{~s}$, the interior of the progress bar would change from yellow to red progressively from left to right as time elapsed without a click, with the bar completely filled after 4 s. Once the progress bar was filled, the message box for point-loss would appear on the screen. If the student clicked the mouse, the progress bar would reset to its initial condition - that is, none of the bar was red. The progress bar appeared above the active task panel.

In addition, an element of accuracy was added to the point-loss contingency. Previously, a click anywhere in the task panel would postpone point-loss regardless of location. Now, only a click on or near the target would postpone point-loss. A click was considered near the target if it occurred within $7 \mathrm{~mm}$ of the boarder of the target. With these modifications it was not possible to avoid losing a point if the student did not attempt to track the target with the cursor. This change was made in an attempt to make the Imposed task more demanding. As outlined in Table 3, in Session 13 the Imposed task level was reset to 3 and Student 1 was placed back in the multiple schedule in order to expose her to the new contingencies. The 
postponement interval was changed from $4 \mathrm{~s}$ to $2 \mathrm{~s}$ in the Imposed task. This change was meant to raise the difficulty of the task by ensuring that the minimum rate of responding required to avoid point-loss would be higher in the Imposed task relative to the Alternate task. All of these changes were intended to increase effort in the Imposed task relative to the Alternate task, however as shown in Figure 2, changeover responding did not increase during Phase 3. No more than three changeover responses occurred during a single session which is less than the previous two phases and well below the acquisition criterion of 12 responses per session.

Accuracy and Earnings - Table 3 shows the accuracy of on-target clicks, total session earnings, and the maximum earnings possible for each session for Student 1 . The maximum earnings possible were determined by dividing $\$ 3.12$ (the programmed maximum earnings per session) by 24 minutes (total time per session) and multiplying the result by the total time spent in the Imposed task during a session. Table 3 shows that Student 1 consistently made less than the maximum possible earnings. In addition, in Sessions 2, 3, 9, and 13, when the Imposed level was never greater than 6 , accuracy for on-target clicks was higher compared to sessions where the task was included Level 7 or 8 . The average accuracy for on-target clicks when the Alternate task was activated was $95 \%$. These results suggest that the effort required to track the target accurately did increase as the level of the Imposed task was raised, and that as accuracy decreased session earnings also decreased, however, changeover responding did not increase as a result.

It was decided that the next step would be to start fresh with a new student since Student 1 was not reliably switching to the Alternate task after multiple manipulations. This was done in order to rule out any idiosyncratic variables specific to the original student, and to control for the effect of experimental history. 
At the end of her last session Student 1 was asked to describe how she made her choices about which task to work in. Part of her responses included a comment that the Alternate task was "boring."

\section{Student 2}

Table 4 summarizes the experimental conditions for every session for Student 2 including the level of the Imposed task, the size of the VI schedule and postponement intervals in each task, and the total time spent in the Imposed task. In addition, Table 4 includes summary information on the number of points gained and lost per session, total session earnings, maximum possible session earnings, and number of clicks on-target, off-target, and near-target with an accuracy measure for the Imposed task.

Figure 4 shows the number of changeover response per session for Student 2. Data sessions that included a multiple schedule were excluded.

Phase 1 - In the first session, the VI schedule remained at $20 \mathrm{~s}$ and the postpone interval remained at $2 \mathrm{~s}$ in the Imposed task and $4 \mathrm{~s}$ in the Alternate task.

As shown in Table 4, by the end of Session 2 the level of the Imposed task had reached 8. As shown in Figure 4, only one changeover response occurred per session for Sessions 2-4. This was well below the acquisition criterion of 12 responses per session so in Session 5, the difficulty of the Imposed task was reset to Level 5 to allow for additional exposure. For all following sessions, the program was adjusted so that the Imposed level was increased manually by the experimenter, and not automatically by the computer program. This change allowed for longer exposure to the task parameters at each level of difficulty, and allowed the experimenter to make adjustments as appropriate based on the data. This change in procedure did not increase 
changeover responding. Figure 4 shows that for Sessions 5 through 8 a total of two changeover responses occurred.

It may be interesting to note that at the end of Session 8 Student 2 made a comment that she had figured out a "better way" to earn points than tracking the target. It was not possible for participants to earn points unless they clicked the target. This comment may suggest that responding for this student was influenced by contingencies outside of the programmed contingencies.

Phase 2 - The purpose of Phase 2 was to address a concern that had been raised by various colleagues about the aversive nature of the Alternate task. Rather than a switch from the Imposed task to the Alternate producing a reduction in task effort, a switch from the Imposed to the Alternate task may have actually functioned as a switch from an interesting task to a relatively boring task. For this reason, the level of the Alternate task was changed to Level 4 (Velocity $=34$ $\mathrm{mm} / \mathrm{s}, 30$ direction changes per min) in the Imposed task.

During the final four sessions with Student 2, the mean rate of changeover responding was 2.75 per session. Since Student 2 still failed to reliably switch from the Imposed to the Alternate task, sessions were terminated.

Accuracy and Earnings - Table 4 shows the accuracy of on-target clicks, total session earnings, and the maximum earnings possible for each session for Student 2. Similar to Student 1, Student 2 consistently made less than the maximum possible earnings. In fact, during Sessions 2, 10, and 11 she actually acquired a deficit in earnings. In addition, as the level of the Imposed task was raised, accuracy for on-target clicks decreased. For Sessions 1, 5, and 6, when the Imposed task level was never more than 6 , the average accuracy for on-target clicks was $52 \%$. The average accuracy for all other sessions, when the Imposed task included either Level 7 or 8, was 33\%. 
Average accuracy for on-target clicks when the alternate task was activated was $73 \%$. These results suggest that the effort required to track the target accurately in the Imposed task did increase as the difficulty of the Imposed task was raised and yet changeover responding did not increase as a result. This is true even when Student 2 earned very little money by tracking the target in the Imposed task.

\section{Student 3}

Table 5 summarizes the experimental conditions for every session for Student 3 including the level of the Imposed task, the size of the VI schedule and postponement intervals in each task, and total time spent in the Imposed task. In addition, Table 5 includes summary information on the number of points gained and lost, total session earnings, maximum possible session earnings, and number of clicks on-target, off-target, and near-target with an accuracy measure for the Imposed task.

Phase 1 - The mean rate of changeover responses per session for Student 3 are shown in Figure 5. Unlike Students 1 and 2, during the initial session with Student 3, the difficulty of the Imposed task was set to Level $6(51 \mathrm{~mm} / \mathrm{s}, 30$ direction changes per min) and the Alternate task was set to Level 4 (Velocity $=34 \mathrm{~mm} / \mathrm{s}, 30$ direction changes per min). The VI schedule remained at $20 \mathrm{~s}$ and the postponement intervals remained at $2 \mathrm{~s}$ in the Imposed task and $4 \mathrm{~s}$ in the Alternate task. As shown in Table 5, by Session 2 the Imposed task had reached Level 8 and, as shown in Figure 5, a total of three changeover responses occurred during this session. Rather than reset the task difficulty as was done with the previous two students, it was decided that changeover responding may increase with prolonged exposure to the current parameters. As such, the same parameters for the Imposed task were kept in place for Sessions 3 through 5. In Session 6 the Alternate task duration was changed from $120 \mathrm{~s}$ to $60 \mathrm{~s}$. No other manipulations were made to the task 
parameters for Sessions 7 through 13. The mean rate of changeover responding for Sessions 3 through 12 was 2.7. In Session 13, the level of the Imposed task was reset to 3 but reached 8 by the end of the session and did not result in an increase in changeover responding.

Phase 2 - One possible explanation for the low rate of changeover responding is that the differences in velocity and directional tendencies of the targets did not represent a difference in task effort as was first assumed. The purpose of Phase 2 was to manipulate the difficulty of the Imposed task by adjusting the postponement interval rather than the behavior of the target. Table 5 outlines the sequence of conditions for Student 3. During all remaining sessions, the level of difficulty for both the Imposed and Alternate tasks was set to 3 (velocity $=34 \mathrm{~mm} / \mathrm{s}, 15$ direction changes per min).

In Figure 5 a change in the postponement interval is indicated by a dotted line. The size of the interval is listed above the sessions that interval was in place for. The size of the postponement interval is listed for the Imposed task first followed by the Alternate task and separated by a comma.

During Sessions 14 through 16 the postponement interval remained at $2 \mathrm{~s}$ in the Imposed task and $4 \mathrm{~s}$ in the Alternate task. Thus, the only difference between the two tasks was how fast the student had to click in order to avoid the loss of a point. A total of 4 changeover responses occurred during each of these three sessions. For Sessions 17 through 22 the schedule of pointloss was equated between the Imposed and Alternate at 4 seconds. Thus, a change from the Imposed task to the Alternate task would produce no change in task parameters. Figure 5 shows that for these sessions, changeover responding was still maintained at four occurrences per session except for Session 20 when it was reduced to two. These results suggest that some rate of 
changeover responding was likely maintained by contingencies outside of the experimental parameters since responding was maintained when there was no difference in task parameters. In Sessions 23 through 26 the postponement interval was changed from $4 \mathrm{~s}$ to $1 \mathrm{~s}$ in the Imposed task and remained at $4 \mathrm{~s}$ in the Alternate task. This manipulation was intended to increase the difficulty of the Imposed task by raising the minimum rate of responding required in the Imposed task relative to the Alternate task to avoid a point deduction. As shown in Figure 5, changeover responding did not increase as a result of this manipulation. In fact, there is a slight decrease in responding. One explanation for the decrease in responding is that pressing the button competed with the student's ability to track the target, and $1 \mathrm{~s}$ was not long enough for them to stop responding on the point production schedule and switch to the changeover button without losing a point.

For Sessions 27 and 28 the postponement interval was reset to from $1 \mathrm{~s}$ to $2 \mathrm{~s}$ in the Imposed task and remained at $4 \mathrm{~s}$ in the Alternate task. As shown in Figure 5, changeover responding continued to decrease. In Sessions 29 through 31 the postponement schedule was changed from 2 $\mathrm{s}$ to $1 \mathrm{~s}$ in the Imposed task and remained at $4 \mathrm{~s}$ in the Alternate task. Responding during these sessions increased to 4 per session, but still failed to meet the acquisition criterion of spending $50 \%$ of session time in the Alternate task.

Accuracy and Earnings - Table 5 shows the accuracy of on-target clicks, total session earnings, and the maximum earnings possible for each session for Student 3. Unlike Students 1 and 2, Student 3 often made close to the maximum possible earnings for a session. In Sessions 6, 16, 19,21 , and 22, Student 3 earned a few more cents than the maximum amount. This is likely due to the way the program rounded total session earnings, which was always to the next highest whole cent. Similar to Students 1 and 2, for Student 3, as the difficulty of the Imposed task was 
raised, her accuracy for on-target clicks decreased. As shown in Table 5, when the Imposed task level was never more than 6 in Sessions 1 and 14 through 31average accuracy was 70\%. When the Imposed task included Levels 7 and 8 in Sessions 2 through 13 average accuracy was 33\%. Average accuracy for on-target clicks when the alternate task was activated was 66\%.These results suggest that the effort required to track the target accurately did increase as the difficulty of the Imposed task was raised. Student 3 was able to earn the maximum amount of money per session consistently however, because her overall average rate of responding per session was higher. Students 1 and 2 made an average of 1250 and 540 on-target clicks respectively per session. Student 3 made an average of 2293 on-target clicks per session. This meant that even though her accuracy decreased as a function of the Imposed task level, she still made enough ontarget clicks to maximize point production.

After her final session, Student 3 was asked how she made her choices about which task to work in. Her response was that she had formulated a rule. She would stay in the Imposed task until she earned a certain amount of points, at which time she would transfer to the Alternate task for a brief "break". It is possible that this self-generated rule overrode the experimental contingencies and would help explain the maintenance of responding during sessions where the parameters of the two tasks were equated.

\section{Discussion}

For all three students, as the level of the Imposed task was raised, accuracy for on-target clicks decreased. These results suggest that the target in the Imposed task did become more difficult to track as the velocity and number of direction changes it made was manipulated. A decrease in accuracy, however, was not sufficient to maintain changeover responding even when session earnings were well below expected rates for Students 1 and 2 . 
Project 1 was based on the assumption that switching from the Imposed task to the Alternate task would represent a reduction in task effort that would function as a reinforcer for conditioning and maintaining a high rate of responding on the changeover button. None of the students included in this study, however, reliably switched from the Imposed task to the Alternate task despite multiple manipulations to the task parameters. As shown in Tables 3, 4, and 5, in contrast to the original hypothesis, all three students choose to spend the majority of their session time working in the Imposed task. The most changeover responses to occur during a single session for any of the students were 6 when the Alternate task duration was $60 \mathrm{~s}$.

One major difference between Miller's study and the current project is the nature of the task that was used. In Miller's study, physical force differentiated the Imposed and Alternate tasks in terms of the number of pounds required to operate a plunger. Physical force can be accurately quantified and measured in terms of newtons. In Project 1, the Imposed and Alternate tasks were differentiated by manipulating the behavior of two separate targets. Unlike Miller's study, there is no obvious method for quantifying the difference in the effort required by the two tasks. For this reason, we do not know if the difference in effort required to operate a 1-lb plunger versus a 20-lb plunger is equal to the difference in effort required to track the target at Level 3 versus Level 8. While this difference should be taken into consideration when interpreting the results, it should also be kept in mind that one goal of this project was to create a method of experimentation that could be easily used across many different labs. As such, a computer was used because they are common in psychology laboratories.

Two of the three students chose to spend the majority of their time working in the Imposed task even when they earned considerably less than the maximum amount possible. One conclusion that may be drawn from these results is that, under some conditions, people prefer to work harder 
for less money. Although the schedules of point-production were equated across both tasks, students reported that they believed they could earn more if they stayed in the Imposed task. One option for exploring this idea may have been to switch the presentation of the tasks such that students remained in the Alternate task unless they pressed the changeover button which would transfer them to the Imposed task for some duration. If they continued to press the changeover button under these conditions, it may be that an inappropriate assumption was made about which task functioned as a reinforcer for the students. It is possible that the behavioral histories of the students had common features that may have influenced the reinforcing function of the Alternate task. For example, many university students have a history of playing video games in which they earn points for completing different tasks. Often, the more difficult the task, the more points they earn. Previous experience with point delivery may have contributed to incorrect assumptions about how the points were delivered throughout the task and changed the reinforcing efficacy of the difficult task. The purpose of Project 2 was to address some of these concerns by creating a new kind of task.

\section{Project 2}

In Project 2, students could earn points exchangeable for money by using the computer keyboard to copy a string of words that appeared on the computer screen. Two different strings of words were available, one in the Imposed task and one in the Alternate task. In the Imposed task the characters of the words were garbled such that they appeared nonsensical to the student. The words in the Alternate task were written in English and followed a story line. Students could only work on one task at a time. Project 2 had three purposes: 1) To identify parameters of the Imposed task that would maintain a changeover response to the Alternate task, 2) To assess the pattern of changeover responding when access to the Alternate task was arranged on a FR 
schedule, and 3) To evaluate whether changeover responding would be maintained when the parameters of the Imposed and Alternate tasks were switched.

Project 2 was based on the assumption that transcribing a nonsensical string of letters and symbols would require more effort than typing meaningful sequences of words. As such, switching from the Imposed task to the Alternate task would represent a reduction in task effort that would function as a reinforcer for conditioning and maintaining responses on a changeover key.

\section{Tasks}

Figure 6 shows the screen display for Project 2 when the Imposed task was activated. At the onset of every session the screen displayed two task panels. The top panel (approximately 229 mm X $38 \mathrm{~mm}$ ) had black boundary lines with a light yellow interior and constituted the Alternate task. The bottom panel (approximately $229 \mathrm{~mm}$ X $38 \mathrm{~mm}$ ) had black boundary lines with a light blue interior and constituted the Imposed task. When a task was activated, it displayed two prompts, one on top of the other, on the left hand side of the panel. The top prompt read "Original:" in bold font and was followed by the string of words to be copied. The bottom prompt read "Copy:" in bold font and was followed by instructions that read "Copy original here \& press Enter." The instructions on the copy line were presented every time the task was activated. Once the student began to type, the instructions disappeared and were replaced by their transcription. When a task was deactivated all text disappeared from the task panel.

The strings of words presented in both the Imposed and Alternate tasks were pulled in sequential order from two novels by Ernest Hemingway, The Old Man and the Sea, and A Farewell to Arms. At least 30 characters were pulled from the text at a time. If the cutoff for a 30 -character string was in the middle of a word, then the entire word was included in the string, so the string 
could be longer but not shorter than 30 characters. Spaces were not included as characters. Quotation marks, hyphens, and accent marks were removed from the original texts to ease transcriptions.

Original prompts in the Alternate task appeared as written in the novels such that students were able to read along with the story. Prompts in the Imposed task were scrambled using two algorithms. The first algorithm rotated each character in the string by 13 places in the alphabet. If, for example, the original character was an "A" it would appear as an "M". If the original character was less than 13 spaces from the end of the alphabet, the algorithm would cycle back to the beginning. If, for example, the original character was an "S" it would appear as an "F". The algorithm preserved the case of the original letter, spaces, and punctuation marks. The second algorithm was used to change $10 \%$ of the characters in the string to symbols. These symbols included $\sim, \#, \wedge, *$,$\} , and [. These symbols were selected because it was assumed that students$ would have little experience typing them compared to more common symbols. The addition of unfamiliar symbols was meant to increase the difficulty of the task by requiring participants to take extra time to locate the symbols on the keyboard.

When a task was deactivated the program bookmarked the point in the story where the student left off so that the next time the task was activated it picked up in the same place. This meant that the student could be at two separate places in the texts in either task depending on how fast they typed. If the student was in the middle of transcribing a string when the task was deactivated, her work was preserved when the task was reactivated.

Monetary Schedule - Points were delivered for correct transcriptions on a probabilistic VI $15 \mathrm{~s}$ schedule. The first response that occurred after the VI schedule had timed out resulted in point delivery with a 0.5 probability. The purpose of this arrangement was to encourage a high 
response rate in both tasks while controlling for the maximum earnings per session. Points were worth 0.07 cents each in all sessions. The schedule of point production was always equated between the Imposed and Alternate tasks.

Each transcription was evaluated for accuracy when the participant pressed the Enter key. If the transcription was correct - that is each character of the transcription was matched to each character of the original string with appropriate spacing - then a prompt appeared on the right hand side of the task panel that read "Good" in red font. If a point was scheduled to be delivered following a correct transcription, then a message box (approximately $50 \mathrm{~mm}$ x $65 \mathrm{~mm}$ ) also appeared in the center of the panel. In black letters against a white background, the message said, "You scored! Click here to collect your point." After the Student clicked the message, the box disappeared and a new string of text appeared. If a reinforcer was not scheduled to be delivered, a new string of text appeared, and the transcription was cleared. When an incorrect transcription occurred the prompt read "Try again." The transcription was cleared from the copy line, and the same original string of words was presented.

During most sessions, a changeover key was available. By pressing the "Esc" key on the upper left hand corner of the keyboard, the student could switch from the Imposed task to the Alternate task for $60 \mathrm{~s}$. When the changeover key was available, a progress bar also appeared on the screen. Figure 7 shows the arrangement of the screen with the addition of the progress bar, when the Imposed task was activated, and the Esc key was available. The progress bar was located above the Alternate task panel (approximately $229 \mathrm{~mm} \mathrm{X} 13 \mathrm{~mm}$ ) and had black boundary lines. The interior of the progress bar would change to light blue from left to right successively as responses on the changeover key fulfilled the FR requirement. If, for example, the student was required to press the Esc key 4 times to affect a changeover, the interior of the progress bar 
would change to light blue progressively from left to right for every response that occurred, with the bar completely filled after 4 responses. At that point, the Imposed task would be deactivated and the Alternate task would be activated for $60 \mathrm{~s}$. Once the Alternate task was activated the interior of the progress bar would begin to empty progressively from right to left for every second that passed, with the bar appearing completely empty after $60 \mathrm{~s}$. At this time the Alternate task would be deactivated and the Imposed task would be activated. The Esc key was only available when the Imposed task was activated except during the reversal phase.

\section{Establishing Imposed Task Parameters}

The purpose of the first two sessions with each student was to identify parameters of the Imposed task that would maintain a changeover response to the Alternate task. During the first session, students were exposed to the parameters of the Imposed and Alternate tasks using a multiple schedule. Figure 8 shows the screen display for this session. At the onset of the session, both task panels were void of text and a prompt appeared below them that read "Press the Uparrow key to activate the top box" in white font. To the left of the prompt, a picture of the four arrows keys located on the bottom right hand of the keyboard was displayed with a yellow box around the Up-arrow key. After the student pressed the Up-arrow key, the prompt was cleared from the screen, and the Alternate task was activated for $120 \mathrm{~s}$. When the Alternate task was deactivated, a second prompt was presented that read "Press the Down-arrow key to activate the bottom box," and the picture of the arrow keys was shown with a blue outline around the Downarrow key. After the student pressed the down arrow, the prompt was cleared from the screen and the Imposed task was activated for $120 \mathrm{~s}$. The tasks were alternated until the session timed out after 24 minutes. 
During Session 2, the student was given a choice of task. The purpose of this session was to evaluate preference for one task over the other. The idea was to continue to raise the difficulty of the Imposed task until students selected the Alternate task at least 3 out of 4 consecutive presentations. Figure 9 shows the screen arrangement for this session. Both task panels appeared on the screen void of all text. At the onset of the session, a prompt appeared below the task panels that read "Choose which box to activate." in white font. The same picture of the arrow keys from the previous session was used with a white outline around both the Up-arrow and Down-arrow keys. By pressing the Up-arrow key the student could activate the Alternate task for 60 s. By pressing the Down-arrow key the student could activate the Imposed task for $60 \mathrm{~s}$. Both students selected the Alternate task at least $75 \%$ of the time during this session without needing to adjust the Imposed task parameters.

\section{Fixed-Ratio Schedule}

Miller found that when escape from the Imposed task to the Alternate task was arranged on a fixed-ratio schedule, subjects showed a break and run pattern of responding. The "break" in this pattern of responding is the time between the offset of a reinforcer and the first response in the ratio, also referred to as a post-reinforcement pause (PRP). This pattern of responding is a common feature of animal studies that arrange the same schedule of reinforcement. The purpose of the fixed-ratio phase of Project 2 was to replicate these findings using the newly developed typing task. In Project 2, the PRP was the time that elapsed between the offset of the Alternate task and a student's first response on the Esc key. In animal studies, as the FR ratio is increased, the PRP also increases. During this phase of Project 2 the FR required to affect a changeover response was successively increased across sessions and effects on the duration of PRP's were evaluated for each student. 
Figure 7 shows the screen display for Project 2 during the FR phase when the Imposed task was activated. At the onset of the third session, the Esc key became available. A picture of the Esc key appeared below the task panels with a prompt to the right of the picture that read "Esc key activated (upper left of keyboard). Press it see what happens." After the first response on the Esc key the prompt was changed to "Esc key activated." This was done in order to expose participants to the new contingency. At this time the progress bar also appeared on the screen.

Initially, a single response on the Esc key would activate the Alternate task for $60 \mathrm{~s}$. Once changeover responding was maintained at a high rate, at least 12 changeover responses for 4 consecutive sessions, the size of the FR schedule was raised across sessions. Adjustments to the FR schedule were made based on session by session results. Typically, the size of the FR schedule was multiplied by 2 every session to produce a new ratio.

For Student 1 changeover responding extinguished at FR 200 and was not recovered when the FR ratio was decreased back to 100 . For this reason, the FR ratio was reset to 1 and the sequence of ratios was presented again. Once the ratio schedule reached 32, multiple sessions were conducted to ensure stability in responding before continuing to the next ratio. If a single response did not occur during a session, the value of the FR ratio was decreased to the previous ratio in the next session in order avoid extinguishing changeover responses entirely. The goal of this phase was to continue to adjust the size of the FR schedule until the average PRP was at least $10 \mathrm{~s}$ and at least 12 changeover responses occurred during a session.

\section{Reversal of Tasks}

The purpose of the task reversal phase was to assess whether changeover responding would be maintained when a changeover response did not produce a reduction in task effort. In Project 1, there was some evidence to suggest that minimal rates of changeover responding were 
being maintained by contingencies outside of the programmed contingencies. For instance, 2 of the 3 students mentioned self-generate rules that influenced their decision to press the changeover button. In addition, when the task parameters were equated for Student 3, changeover responding still occurred.

During the task reversal phase of Project 2, the experimental contingencies were switched such that the Imposed task became the Alternate task and the Alternate task became the Imposed task. Thus, the student would begin in the standard text task and by pressing the Esc key they would switch to the garbled text task for $60 \mathrm{~s}$. The standard text was still presented in the yellow panel and the garbled text was still presented in the blue panel. For clarity, the two tasks will be referred to as the Standard task and the Garbled task during this portion of the project. It was assumed that responding on the Esc key in this condition would be extinguished because the switch from a relatively easy task to a relatively difficult task would not function as a reinforcer for maintaining the changeover response. For this phase of Project 2, the FR schedule was always set to 1 .

\section{Results}

Figures 10 and 11 show the exact sequence of conditions and the mean PRP in seconds for each session for Students 4 and 5 respectively. Changeover responding, for both students, could be described as all or nothing. Rather than seeing a gradual increase in the PRP as a function of the ratio requirement as expected, either a very high rate of responding, or a very low rate of responding occurs. Often, at the onset of a session, participants would immediately press the Esc key a few times. Then, they would both continue responding until the ratio was complete, and continue to respond at a high rate throughout the session, or they would stop responding on the Esc key for the duration of the session. It is possible that students engaged in a 
few initial responses to "test the waters" or estimate the number of responses required to switch to the Alternate task based on feedback from the progress bar, and then make a decision about whether or not to complete the ratio.

Figures 12 and 13 show the number of changeover responses per session for Students 4 and 5 respectively during the reversal phase of Project 2. During Sessions 1 through 4 a changeover response would switch the student from the Standard task to the Garbled task for 60 s. For Student 4, 1 changeover response occurred in the first session of the phase. Changeover responding for both students during the rest of the sessions was zero. During Sessions 5 through 8 , the tasks were switched such that a changeover response switched the participant from the Garbled task to the Standard task. A total of 24 responses occurred per session for each student during these sessions. This was the maximum number of responses possible during a single session since sessions were $24 \mathrm{~min}$. During Sessions 9 through 12 the tasks were reversed to the original parameters such that a changeover response would switch the participants from the Standard task to the Garbled task. Changeover responding during these sessions extinguished for both students. These results suggest that a switch from a relatively difficult task to a relatively easy task functioned as a reinforcer for maintaining changeover responding whereas a switch from a relatively easy task to a relatively difficult task did not.

\section{Accuracy and Earnings}

Table 6 provides summary information for Students 4 and 5 on the average number of correct and incorrect transcriptions, accuracy, number of points gained, and session earnings for both the Imposed and Alternate tasks. Results are based on per session averages. Only sessions where a task was activated at least once were included in the calculation. This table shows that both students completed more transcriptions in the Alternate task and were more accurate with 
their transcriptions in the Alternate task. These results support the idea that completing correct transcriptions in the Alternate task required less effort compared to completing correct transcriptions in the Imposed task.

\section{General Discussion}

The results from Project 2 support Miller's findings that a reduction in task effort may function as reinforcer for conditioning and maintaining a changeover response. The results from Project 1 however, where participants never acquired the changeover response are inconclusive. The results from Project 1 should be interpreted with some caution. This work was exploratory in nature. For this reason, certain assumptions were made a priori. One of these assumptions was that students would prefer to track a slower target over a faster target when given an option between the two. In Project 1, we did not assess preference for one task over the other before attempting to condition a changeover response. It is possible that students failed to acquire the changeover response because switching from the Imposed task to the Alternate task did not actually represent a reduction in effort that was reinforcing to the student. When the task was redesigned in Project 2, and preference for one task over the other was assessed, both students acquired the changeover response.

In Project 2, after changeover responding was established students did not show a break-and-run pattern of responding when a when access to the Alternate task was arranged on a FR schedule. One explanation for the differing results is that a computer based task is not functionally equivalent to a task based on physical force such as lifting weights and may have a different effect on behavior.

Another explanation is that certain components of the computer task changed the way the programmed contingencies influenced performance. For example, the addition of the progress bar provided a signal for the number of responses required to complete a ratio to the student. 
This may have changed performance on the schedule in effect by making the FR schedule more predictable and it is possible that if the program was redesigned without this signal, students would have shown a different pattern of responding.

This study look at patterns of responding using a FR schedule but it might be beneficial to assess performance with different schedules of reinforcement. For example, when fixed-interval schedules of reinforcement are arranged with animal subjects they typically produce a distinct scalloped pattern of responding where only a few responses occur towards the end of an interval. It is possible that arranging access to the Alternate task on a different schedule of reinforcement, such as a fixed-interval, may produce a different pattern of responding that would closely resemble animal performance.

Using the reduction in task effort as a reinforcer has implications for human operant studies because it is a reinforcer that addresses key differences between reinforcers that are typically used with animal subjects, and reinforcers that are typically used with human subjects as outlined in Table 1. That is, a reduction in task effort is a reinforcer that is consumed in the moment, contacted at the time of delivery, and the factors that influence the efficacy of the reinforcer can be manipulated by the experimenter. By better equating experimental conditions we can begin to tease apart the factors that differentially effect human and animal performance.

Taken alone, the results from the current study seem to support the idea that discrepancies between human and animal performances are due to fundamental differences between species, however this conclusion would be premature. It is possible that there were additional uncontrolled variables that influenced performance. Some evidence for this is provided by the student's comments on how the program worked. Before conclusions should be drawn about 
overarching principles of behaviors, additional attempts should be made to better equate experimental conditions and identify factors controlling behavior. 


\section{References}

Bickel, W. K., DeGrandpre, R. J., Hughes, J. R., \& Higgins, S. T. (1991). Behavioral economics of drug self-administration. II. A unit-price analysis of cigarette smoking. Journal of the Experimental Analysis of Behavior, 55, 145-154.

Brewer, W. F. (1974). There is no convincing evidence for operant or classical conditioning in adult humans. In W.B. Weimer and D.S. Palermo(eds), Cognition and the Symbolic

Processes. Hillsdale, NJ: Erlbaum, pp. 1-33.

Catania, A. C. (1998). Learning (4 ${ }^{\text {th }}$ ed.). New Jersey: Upper Saddle River.

Crossman, E. K. (1968). Pause relationships in multiple and chained fixed-ratio schedules. Journal of the Experimental Analysis of Behavior, 11, 117-126.

Ferster, C. B. and Skinner, B. F.(1957). Schedules of Reinforcement. New York: AppletonCentury-Crofts.

Fleshler, M., \& Hoffman, H. S. (1962). A progression for generating variable-interval schedules. Journal of the Experimental Analysis of Behavior, 5, 529-530.

Galizio, M., Buskist, W. (1988). Laboratory Lore and Research Practices in the Experimental Analysis of Human Behavior: Selecting Reinforcers and Arranging Contingencies. The Behavior Analyst, 11, 65-69.

Kollins, S., Newland, M. C., \& Critchfield, T. (1997). Human sensitivity to reinforcement in operant choice: How much do consequences matter? Psychonomic Bulletin \& Review, 4 (2), 208-220.

Lowe, C. F. (1979). Determinants of human operant behavior. In M.D. Zeiler and P. Harzem (eds), Advances in the Analysis of Behavior: Vol. 1. Reinforcement and the Organization of Behaviour, New York: Wiley, pp. 159-192. 
Lowe, C. F., \& Harzem, P. (1977). Species differences in temporal control of behavior. Journal of the Experimental Analysis of Behavior, 28, 189-201.

Madden, G. J., \& Perone, M. (1999). Human sensitivity to concurrent schedules of reinforcement: Effects of observing schedule-correlated stimuli. Journal of the Experimental Analysis of Behavior, 71, 303-318.

Matthews, B. A., Shimoff, E., Catania, A. C., \& Sagvolden, T. (1977). Uninstructed human responding: Sensitivity to ratio and interval contingencies. Journal of the Experimental Analysis of Behavior, 27, 453-467.

Miller, L. K. (1968). Escape from an effortful situation. Journal of the Experimental Analysis of Behavior, 11, 619-627.

Navarick, D. J. (1982). Negative reinforcement and choice in humans. Learning and Motivation, 13 (3), 361-377.

Perone, M., \& Courtney, K. (1992). Fixed-ratio pausing: Joint effects of past reinforcer magnitude and stimuli correlated with upcoming magnitude. Journal of the Experimental Analysis of Behavior, 57, 33-46.

Peron, M., Galizio, M., \& Baron, A. (1988). The Relevance of Animal-Based Principles in the Laboratory Study of Human Operant Conditioning. In Davey, G., Cullen, C. (eds), Human Operant Conditioning and Behavior Modification. (pp. 59-85). New York: John Wiley \& Sons.

Weiner, H. (1969). Controlling human fixed-interval performance. Journal of the Experimental Analysis of Behavior, 12, 349-373. 
Table 1. Key issues to be addressed between points or money (typically used in human operant studies) and food (typically used in animal studies) as reinforcers.

\begin{tabular}{lll}
\hline & Points/Money & Food \\
\hline \hline 1) & $\begin{array}{l}\text { Subject's contact } \\
\text { with the } \\
\text { reinforcer after } \\
\text { delivery is } \\
\text { assumed }\end{array}$ & $\begin{array}{l}\text { Subject's contact } \\
\text { with reinforcer after } \\
\text { delivery is assured }\end{array}$ \\
\hline 2) & $\begin{array}{l}\text { Reinforcer is not } \\
\text { consumed } \\
\text { immediately by } \\
\text { the subject }\end{array}$ & $\begin{array}{l}\text { Reinforcer is } \\
\text { consumed } \\
\text { immediately by the } \\
\text { subject }\end{array}$ \\
\hline 3) & $\begin{array}{l}\text { Establishing } \\
\text { operations are } \\
\text { absent }\end{array}$ & $\begin{array}{l}\text { Establishing } \\
\text { operations are under } \\
\text { experimental control }\end{array}$ \\
\hline
\end{tabular}




\begin{tabular}{lcc}
\hline $\begin{array}{l}\text { Table 2. Parameters of target behavior: Velocity and } \\
\text { rate of spontaneous changes in direction. }\end{array}$ \\
\hline Task & $\begin{array}{l}\text { Velocity } \\
(\mathrm{mm} / \mathrm{s})\end{array}$ & $\begin{array}{l}\text { Direction Changes } \\
\text { per Min }\end{array}$ \\
\hline Alternate & 11 & 0 \\
Imposed 1 & 17 & 15 \\
Imposed 2 & 17 & 30 \\
Imposed 3 & 34 & 30 \\
Imposed 4 & 34 & 15 \\
Imposed 5 & 51 & 30 \\
Imposed 6 & 51 & 15 \\
Imposed 7 & 67 & 30 \\
Imposed 8 & 67 & \\
\hline
\end{tabular}

Note: Relative to the upper (north) and left (west) boundaries of the task rectangle, the target could move northwest, northeast, southwest, or southeast. 
Table 3. Session by session data for Student 1 in Project 1. The abbreviation MULT is used for sessions where a multiple schedule was in place. Only data collected during the Imposed task is displayed. Lines separate phase changes.

\begin{tabular}{|c|c|c|c|c|c|c|c|c|c|c|c|c|c|c|c|}
\hline Session & Phase & $\begin{array}{l}\text { Level of } \\
\text { Imposed } \\
\text { Task }\end{array}$ & $\begin{array}{c}\text { Imposed } \\
\text { Postponement } \\
\text { Interval }\end{array}$ & $\begin{array}{c}\text { Alternate } \\
\text { Postponement } \\
\text { Interval }\end{array}$ & $\begin{array}{c}\text { Alternate } \\
\text { Task } \\
\text { Duration }\end{array}$ & $\begin{array}{l}\text { VI Point } \\
\text { Production } \\
\text { ( s })\end{array}$ & $\begin{array}{l}\text { Point } \\
\text { Loss }\end{array}$ & $\begin{array}{l}\text { Point } \\
\text { Gain }\end{array}$ & $\begin{array}{c}\text { Session } \\
\text { Earnings } \\
(\$)\end{array}$ & $\begin{array}{c}\text { Max } \\
\text { Earnings } \\
(\$)\end{array}$ & $\begin{array}{c}\text { Total } \\
\text { Time in } \\
\text { Seconds }\end{array}$ & $\begin{array}{c}\text { On } \\
\text { Target } \\
\text { Clicks }\end{array}$ & $\begin{array}{c}\text { Off } \\
\text { target } \\
\text { Clicks }\end{array}$ & $\begin{array}{l}\text { Near } \\
\text { target } \\
\text { Clicks }\end{array}$ & $\begin{array}{c}\% \\
\text { Accuracy }\end{array}$ \\
\hline 1 & MULT & 3 & 4 & 4 & 60 & 30 & 0 & 13 & 0.87 & 2.33 & 1058 & 424 & 148 & - & 75 \\
\hline 2 & 1 & 3 & 4 & 4 & 60 & 30 & 0 & 0 & - & 3.17 & 1440 & 129 & 31 & - & 81 \\
\hline 3 & 1 & $3-6$ & 4 & 4 & 60 & 30 & 1 & 18 & 1.14 & 2.77 & 1260 & 946 & 580 & - & 62 \\
\hline 4 & 1 & $6-8$ & 4 & 4 & 60 & 30 & 0 & 30 & 2.01 & 2.38 & 1080 & 1109 & 1896 & - & 37 \\
\hline 5 & 1 & $5-8$ & 4 & 4 & 60 & 30 & 2 & 28 & 1.74 & 2.38 & 1080 & 1603 & 1926 & - & 45 \\
\hline 6 & 1 & 8 & 4 & 4 & 60 & 30 & 1 & 33 & 2.14 & 2.51 & 1140 & 1331 & 2450 & - & 35 \\
\hline 7 & 1 & 8 & 4 & 4 & 60 & 30 & 1 & 31 & 2.01 & 2.51 & 1139 & 1392 & 2618 & - & 35 \\
\hline 8 & 1 & 8 & 4 & 4 & 60 & 30 & 2 & 24 & 1.47 & 2.39 & 1087 & 1083 & 2233 & - & 33 \\
\hline 9 & MULT & 3 & 4 & 4 & 120 & 20 & 0 & 28 & 1.26 & 1.63 & 742 & 2032 & 556 & - & 79 \\
\hline 10 & 2 & $3-8$ & 4 & 4 & 120 & 20 & 0 & 38 & 1.71 & 2.11 & 960 & 1872 & 1508 & - & 55 \\
\hline 11 & 2 & 8 & 4 & 4 & 120 & 20 & 0 & 42 & 1.89 & 2.34 & 1062 & 1248 & 2162 & - & 37 \\
\hline 12 & 2 & 8 & 4 & 4 & 120 & 20 & 1 & 43 & 1.89 & 2.36 & 1074 & 1049 & 2438 & - & 30 \\
\hline 13 & MULT & $3-4$ & 4 & 4 & 120 & 20 & 1 & 32 & 1.40 & 1.75 & 795 & 2108 & 57 & 660 & 75 \\
\hline 14 & 3 & $4-8$ & 4 & 4 & 120 & 20 & 7 & 41 & 1.53 & 2.38 & 1080 & 1516 & 404 & 1682 & 42 \\
\hline 15 & 3 & 8 & 4 & 4 & 120 & 20 & 3 & 38 & 1.58 & 2.11 & 959 & 1066 & 436 & 1602 & 34 \\
\hline 16 & 3 & 8 & 4 & 4 & 120 & 20 & 1 & 38 & 1.67 & 2.37 & 1079 & 1107 & 525 & 1750 & 33 \\
\hline
\end{tabular}


Table 4. Session by session data for Student 2 in Project 1. The abbreviation MULT is used for sessions where a multiple schedule was in place. Only data collected during the Imposed task is displayed. Numbers listed under session earnings with parentheses around them are negative amounts. Lines separate phase changes.

\begin{tabular}{|c|c|c|c|c|c|c|c|c|c|c|c|c|c|c|c|}
\hline Session & Phase & $\begin{array}{c}\text { Level of } \\
\text { Imposed } \\
\text { Task }\end{array}$ & $\begin{array}{c}\text { Imposed } \\
\text { Postponement } \\
\text { Interval } \\
\end{array}$ & $\begin{array}{c}\text { Alternate } \\
\text { Postponement } \\
\text { Interval } \\
\end{array}$ & $\begin{array}{l}\text { Alternate } \\
\text { Task } \\
\text { Duration }\end{array}$ & $\begin{array}{l}\text { VI Point } \\
\text { Production } \\
(\mathrm{s})\end{array}$ & $\begin{array}{l}\text { Point } \\
\text { Loss }\end{array}$ & $\begin{array}{l}\text { Point } \\
\text { Gain }\end{array}$ & $\begin{array}{c}\text { Session } \\
\text { Earnings } \\
(\$)\end{array}$ & $\begin{array}{c}\text { Max } \\
\text { Earnings } \\
(\$)\end{array}$ & $\begin{array}{l}\text { Total } \\
\text { Time }\end{array}$ & $\begin{array}{c}\text { On } \\
\text { Target } \\
\text { Clicks } \\
\end{array}$ & $\begin{array}{c}\text { Off } \\
\text { target } \\
\text { Clicks } \\
\end{array}$ & $\begin{array}{c}\text { Near } \\
\text { Target } \\
\text { Clicks }\end{array}$ & $\begin{array}{c}\% \\
\text { Accuracy }\end{array}$ \\
\hline 1 & MULT & $3-4$ & 2 & 4 & 120 & 20 & 20 & 35 & 0.69 & 1.72 & 780.8 & 548 & 11 & 259 & 67 \\
\hline 2 & 1 & $4-8$ & 2 & 4 & 120 & 20 & 48 & 47 & $(0.05)$ & 2.89 & 1315.0 & 534 & 115 & 592 & 43 \\
\hline 3 & 1 & 8 & 2 & 4 & 120 & 20 & 26 & 48 & 1.01 & 2.90 & 1320.0 & 411 & 267 & 907 & 26 \\
\hline 4 & 1 & 8 & 2 & 4 & 120 & 20 & 30 & 54 & 1.10 & 2.90 & 1320.0 & 460 & 382 & 1133 & 23 \\
\hline 5 & 1 & 5 & 2 & 4 & 120 & 20 & 19 & 60 & 1.89 & 3.17 & 1439.9 & 604 & 70 & 696 & 44 \\
\hline 6 & 1 & 6 & 2 & 4 & 120 & 20 & 10 & 64 & 2.48 & 3.17 & 1440.0 & 738 & 111 & 819 & 44 \\
\hline 7 & 1 & 7 & 2 & 4 & 120 & 20 & 8 & 64 & 2.58 & 3.17 & 1440.0 & 742 & 119 & 881 & 43 \\
\hline 8 & 1 & 7 & 2 & 4 & 120 & 20 & 14 & 55 & 1.89 & 2.64 & 1200.0 & 584 & 90 & 708 & 42 \\
\hline 9 & 2 & 8 & 2 & 4 & 60 & 20 & 22 & 58 & 2.52 & 2.90 & 1320.0 & 433 & 218 & 808 & 30 \\
\hline 10 & 2 & 8 & 1 & 2 & 60 & 20 & 78 & 34 & $(3.08)$ & 1.96 & 889.9 & 388 & 251 & 778 & 27 \\
\hline 11 & 2 & 8 & 1 & 2 & 60 & 20 & 94 & 48 & $(3.22)$ & 2.64 & 1200.0 & 549 & 186 & 902 & 34 \\
\hline 12 & 2 & 8 & 2 & 2 & 60 & 20 & 18 & 57 & 2.73 & 2.90 & 1320.0 & 495 & 237 & 875 & 31 \\
\hline
\end{tabular}


Table 5. Session by session data for Student 3 in Project 1. The abbreviation MULT is used for sessions where a multiple schedule was in place.

Only data collected during the Imposed task is displayed. Lines separate changes in the postponement interval.

\begin{tabular}{|c|c|c|c|c|c|c|c|c|c|c|c|c|c|c|c|}
\hline Session & Phase & $\begin{array}{c}\text { Level of } \\
\text { Imposed } \\
\text { Task }\end{array}$ & $\begin{array}{c}\text { Imposed } \\
\text { Postponement } \\
\text { Interval }\end{array}$ & $\begin{array}{c}\text { Alternate } \\
\text { Postponement } \\
\text { Interval }\end{array}$ & $\begin{array}{c}\text { Alternate } \\
\text { Task } \\
\text { Duration }\end{array}$ & $\begin{array}{l}\text { VI Point } \\
\text { Production } \\
\quad(\mathrm{s})\end{array}$ & $\begin{array}{l}\text { Point } \\
\text { Loss }\end{array}$ & $\begin{array}{l}\text { Point } \\
\text { Gain }\end{array}$ & $\begin{array}{l}\text { Session } \\
\text { Earnings } \\
\quad(\$)\end{array}$ & $\begin{array}{c}\text { Max } \\
\text { Earnings } \\
(\$)\end{array}$ & $\begin{array}{l}\text { Total } \\
\text { Time }\end{array}$ & $\begin{array}{c}\text { On } \\
\text { Target } \\
\text { Clicks }\end{array}$ & $\begin{array}{c}\text { Off } \\
\text { target } \\
\text { Clicks }\end{array}$ & $\begin{array}{l}\text { Near } \\
\text { Target } \\
\text { Clicks }\end{array}$ & $\begin{array}{c}\% \\
\text { Accuracy }\end{array}$ \\
\hline 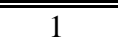 &  & " & 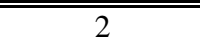 &  & " 120 & 20 & 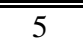 & "31 & "1.20 & "1.50 & $=680.7$ & 897 & 88 & "704 & " 53 \\
\hline 2 & 1 & $6-8$ & 2 & 4 & 120 & 20 & 2 & 38 & 1.66 & 1.85 & 840.0 & 925 & 288 & 1250 & 38 \\
\hline 3 & 1 & 8 & 2 & 4 & 120 & 20 & 0 & 38 & 1.75 & 1.85 & 840.0 & 833 & 454 & 1413 & 31 \\
\hline 5 & 1 & 8 & 2 & 4 & 120 & 20 & 0 & 37 & 1.70 & 1.85 & 840.0 & 751 & 509 & 1548 & 27 \\
\hline 6 & 1 & 8 & 2 & 4 & 60 & 20 & 0 & 49 & 2.25 & 2.24 & 1019.5 & 1120 & 621 & 1930 & 31 \\
\hline 7 & 1 & 8 & 2 & 4 & 60 & 20 & 0 & 48 & 2.21 & 2.24 & 1020.0 & 1054 & 602 & 2065 & 28 \\
\hline 8 & 1 & 8 & 2 & 4 & 60 & 20 & 2 & 49 & 2.16 & 2.38 & 1080.0 & 1148 & 656 & 2006 & 30 \\
\hline 9 & 1 & 8 & 2 & 4 & 60 & 20 & 0 & 44 & 2.02 & 2.24 & 1019.7 & 1107 & 672 & 1828 & 31 \\
\hline 10 & 1 & 8 & 2 & 4 & 60 & 20 & 1 & 54 & 2.44 & 2.51 & 1140.0 & 1127 & 709 & 2084 & 29 \\
\hline 11 & 1 & 8 & 2 & 4 & 60 & 20 & 0 & 51 & 2.35 & 2.51 & 1140.0 & 1321 & 635 & 2121 & 32 \\
\hline 12 & 1 & 8 & 2 & 4 & 60 & 20 & 1 & 48 & 2.16 & 2.38 & 1080.0 & 1093 & 643 & 1979 & 29 \\
\hline 13 & 2 & $3-8$ & 2 & 4 & 60 & 20 & 0 & 48 & 2.21 & 2.24 & 1020.0 & 2099 & 179 & 1316 & 58 \\
\hline 14 & 2 & 3 & 2 & 4 & 60 & 20 & 0 & 48 & 2.21 & 2.24 & 1020.0 & 2510 & 93 & 1048 & 69 \\
\hline 15 & 2 & 3 & 2 & 4 & 60 & 20 & 0 & 55 & 2.53 & 2.64 & 1200.0 & 3131 & 108 & 1230 & 70 \\
\hline 16 & 2 & 3 & 2 & 4 & 60 & 20 & 0 & 55 & 2.53 & 2.51 & 1140.0 & 2858 & 118 & 1101 & 70 \\
\hline 17 & 2 & 3 & 4 & 4 & 60 & 20 & 0 & 54 & 2.48 & 2.52 & 1143.6 & 3229 & 95 & 1052 & 74 \\
\hline 18 & 2 & 3 & 4 & 4 & 60 & 20 & 0 & 55 & 2.53 & 2.64 & 1200.0 & 3170 & 85 & 1179 & 71 \\
\hline 19 & 2 & 3 & 4 & 4 & 60 & 20 & 0 & 58 & 2.67 & 2.66 & 1207.5 & 3567 & 105 & 1023 & 76 \\
\hline 20 & 2 & 3 & 4 & 4 & 60 & 20 & 0 & 61 & 2.81 & 2.93 & 1331.5 & 3538 & 120 & 1225 & 72 \\
\hline 21 & 2 & 3 & 4 & 4 & 60 & 20 & 0 & 57 & 2.62 & 2.59 & 1177.7 & 3325 & 90 & 1080 & 74 \\
\hline 22 & 2 & 3 & 4 & 4 & 60 & 20 & 0 & 58 & 2.67 & 2.64 & 1200.0 & 3049 & 118 & 1166 & 70 \\
\hline
\end{tabular}


Developing a Practical Reinforcer -- 43

\begin{tabular}{|c|c|c|c|c|c|c|c|c|c|c|c|c|c|c|c|}
\hline 24 & 2 & 3 & 1 & 4 & 60 & 20 & 7 & 55 & 2.21 & 2.64 & 1200.0 & 3010 & 113 & 1154 & 70 \\
\hline 25 & 2 & 3 & 1 & 4 & 60 & 20 & 4 & 59 & 2.53 & 2.77 & 1260.0 & 3284 & 112 & 1282 & 70 \\
\hline 26 & 2 & 3 & 1 & 4 & 60 & 20 & 3 & 54 & 2.35 & 2.77 & 1260.0 & 2959 & 141 & 1420 & 65 \\
\hline 27 & 2 & 3 & 2 & 4 & 60 & 20 & 0 & 62 & 2.85 & 2.90 & 1320.0 & 3860 & 78 & 1099 & 77 \\
\hline 28 & 2 & 3 & 2 & 4 & 60 & 20 & 0 & 68 & 3.13 & 3.17 & 1440.0 & 3786 & 97 & 1376 & 72 \\
\hline 29 & 2 & 3 & 1 & 4 & 60 & 20 & 3 & 53 & 2.30 & 2.51 & 1140.0 & 3125 & 73 & 1078 & 73 \\
\hline 30 & 2 & 3 & 1 & 4 & 60 & 20 & 1 & 51 & 2.30 & 2.51 & 1140.0 & 2881 & 119 & 1101 & 70 \\
\hline 31 & 2 & 3 & 1 & 4 & 60 & 20 & 3 & 49 & 2.12 & 2.38 & 1080.0 & 2517 & 117 & 1195 & 66 \\
\hline
\end{tabular}


Table 6. Shows summary results for Students 4 and 5 in Project 2 expressed as a per-session means. Only sessions where a task was activated at least once were included in the calculation.

\begin{tabular}{lcccc}
\hline & \multicolumn{2}{c}{ Student 4 } & \multicolumn{2}{c}{ Student 5 } \\
\hline & Imposed task & Alternate task & Imposed task & Alternate task \\
\hline Correct Transcriptions & 11 & 130 & 32 & 209 \\
Incorrect Transcriptions & 2 & 7 & 7 & 5 \\
Accuracy & 85 & 95 & 82 & 98 \\
Points & 4 & 40 & 13 & 51 \\
Session Earnings & 0.28 & 2.8 & 0.91 & 3.57 \\
\hline
\end{tabular}




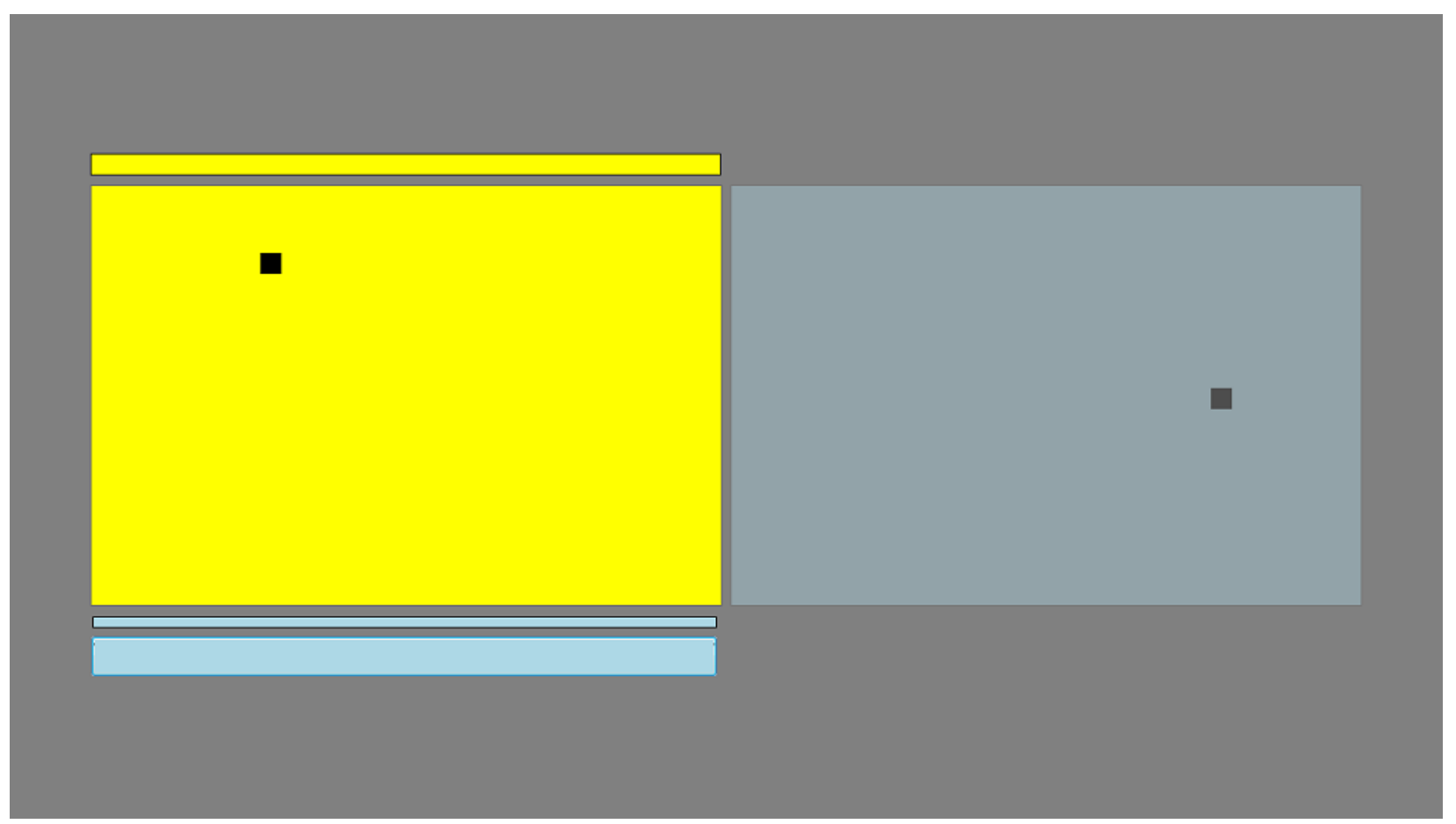

Figure 1. Original screen display for Project 1 when the Imposed task was activated. The left panel constitutes the Imposed task and the right panel constitutes the Alternate task. The rectangle below the left panel is the changeover button. 
Developing a Practical Reinforcer -- 46

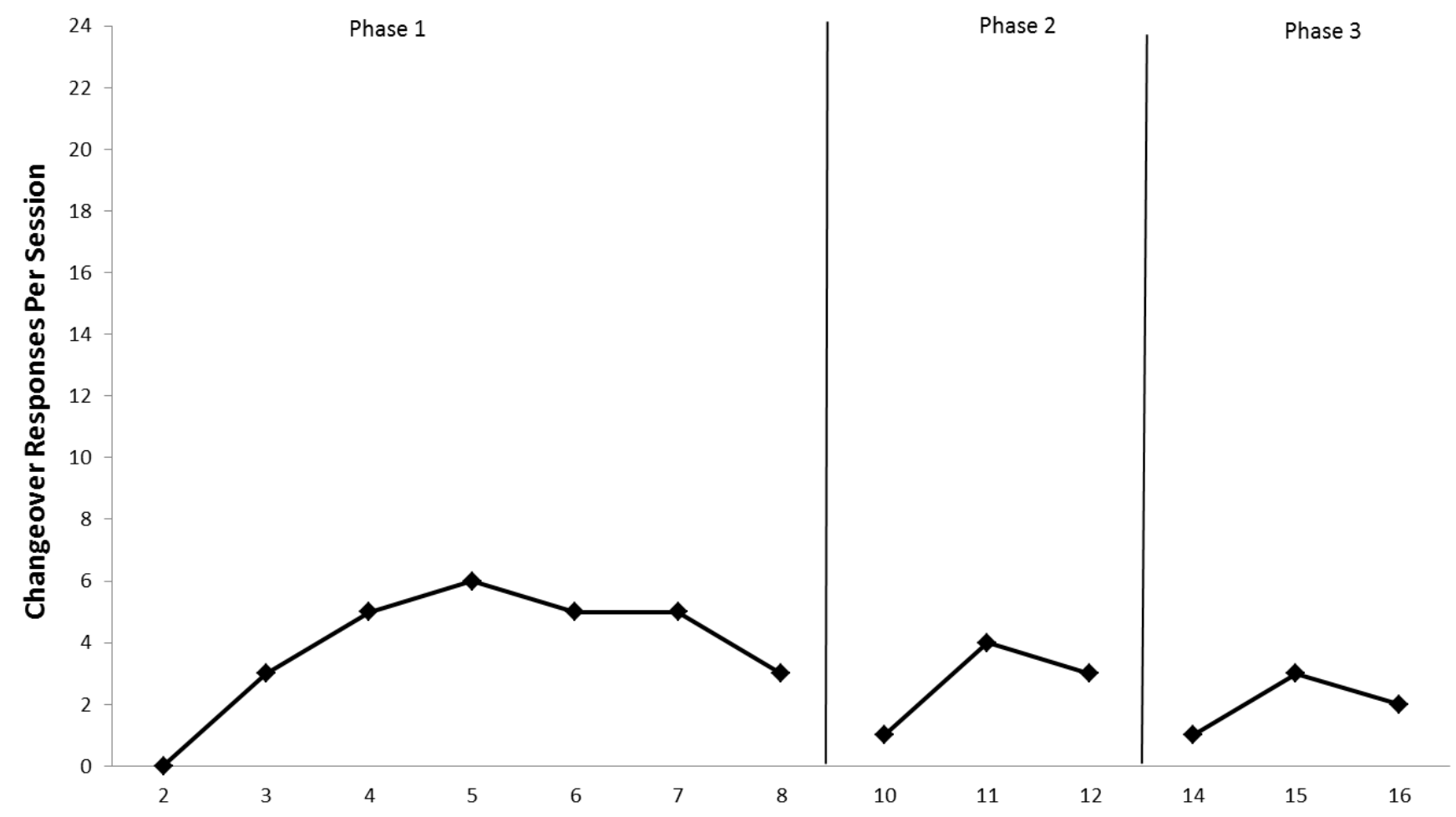

Figure 2. Number of changeover responses per session for Student 1 in Project 1. 


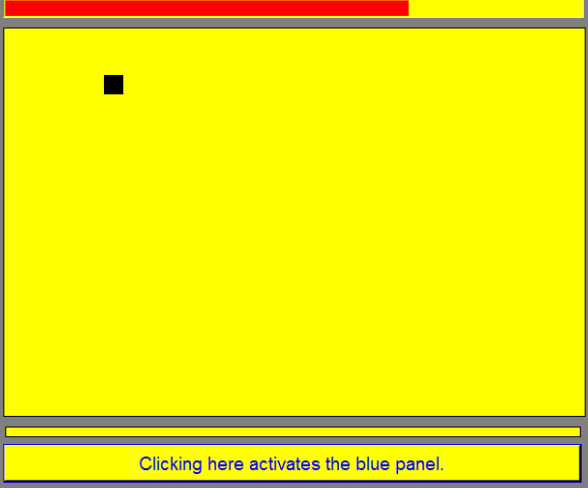

Figure 3. Revised screen display for Project 1 when the Imposed task was activated. The bar above the left task panel constitutes the progress bar for the point-loss postponement schedule. Instructions were also added to the changeover button. 




Figure 4. Number of changeover responses per session for Student 2 in Project 1. 


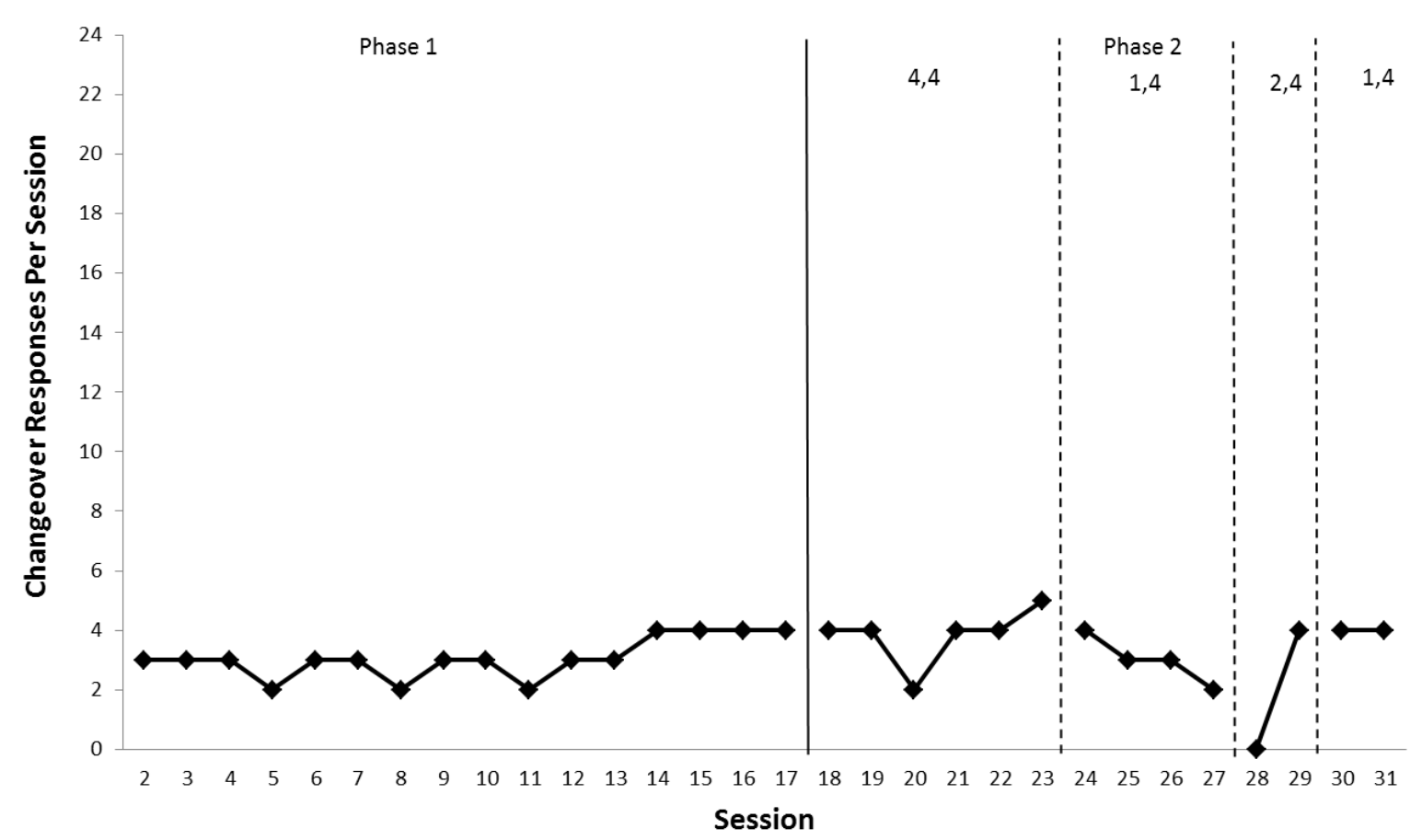

Figure 5. Number of changeover responses per session for Student 3 in Project 1. During Phase 1 the velocity and directional changes of the target were manipulated by adjusted the Imposed task level as displayed in Table 4. During Phase 2 the postponement interval was manipulated. The size of the interval is listed for the Imposed task first followed by the Alternate task and separated by a comma. Changes in the postponement interval are separated by a dotted line. 
Original: Gur 8yq zna naq gur Frn ol Rearfg

Copy: copy original here \& press anter

Figure 6. Sample screen display for Project 2. Here the Imposed task is activated and the Esc key is unavailable. The bottom, light blue panel, where the string of words is garbled, is the Imposed task. The top, light yellow panel is the Alternate task. 


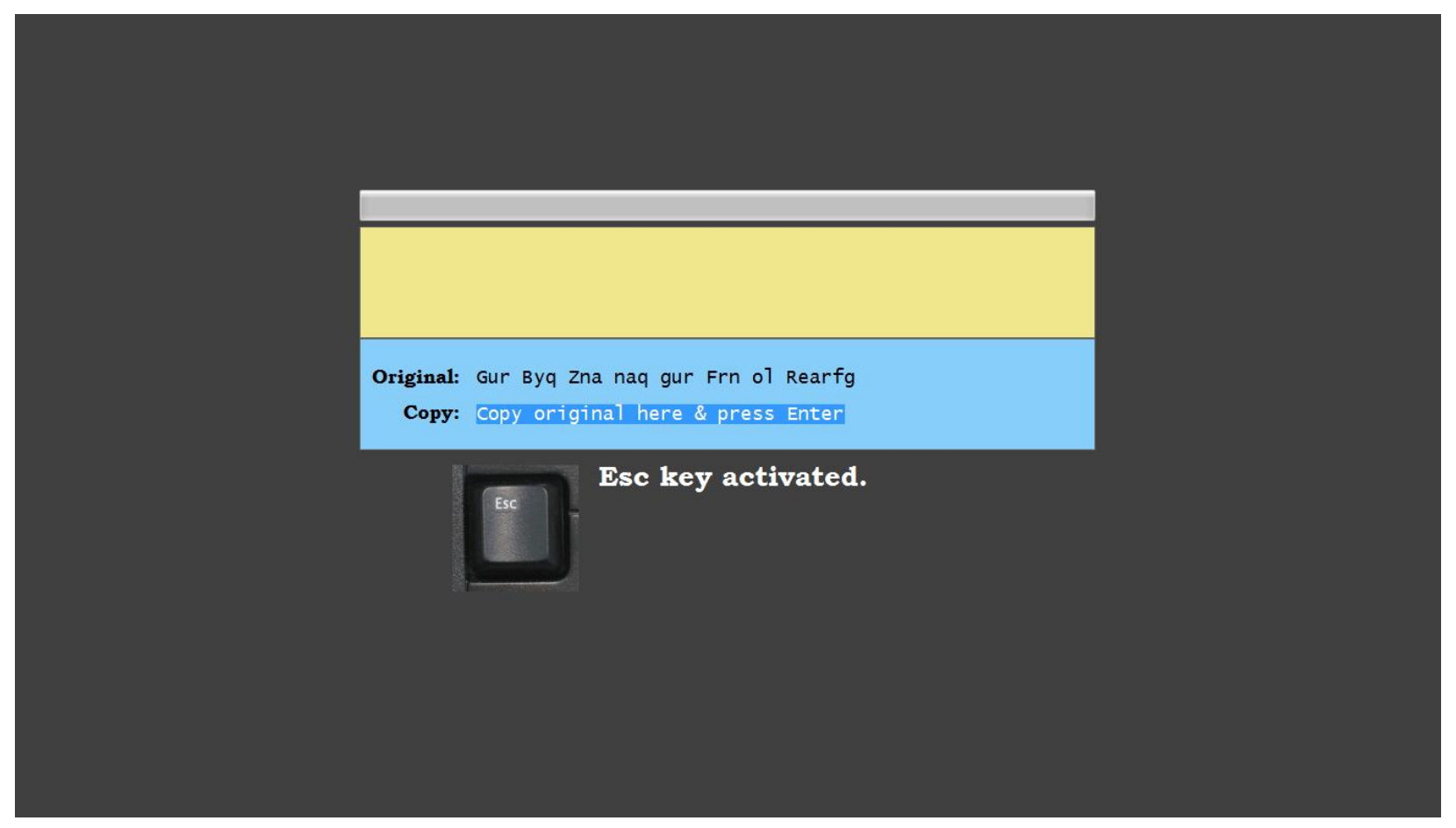

Figure 7. Screen display for the fixed-ratio and reversal phases of Project 2 when the Garbled Task was activated and the Esc key was available. 


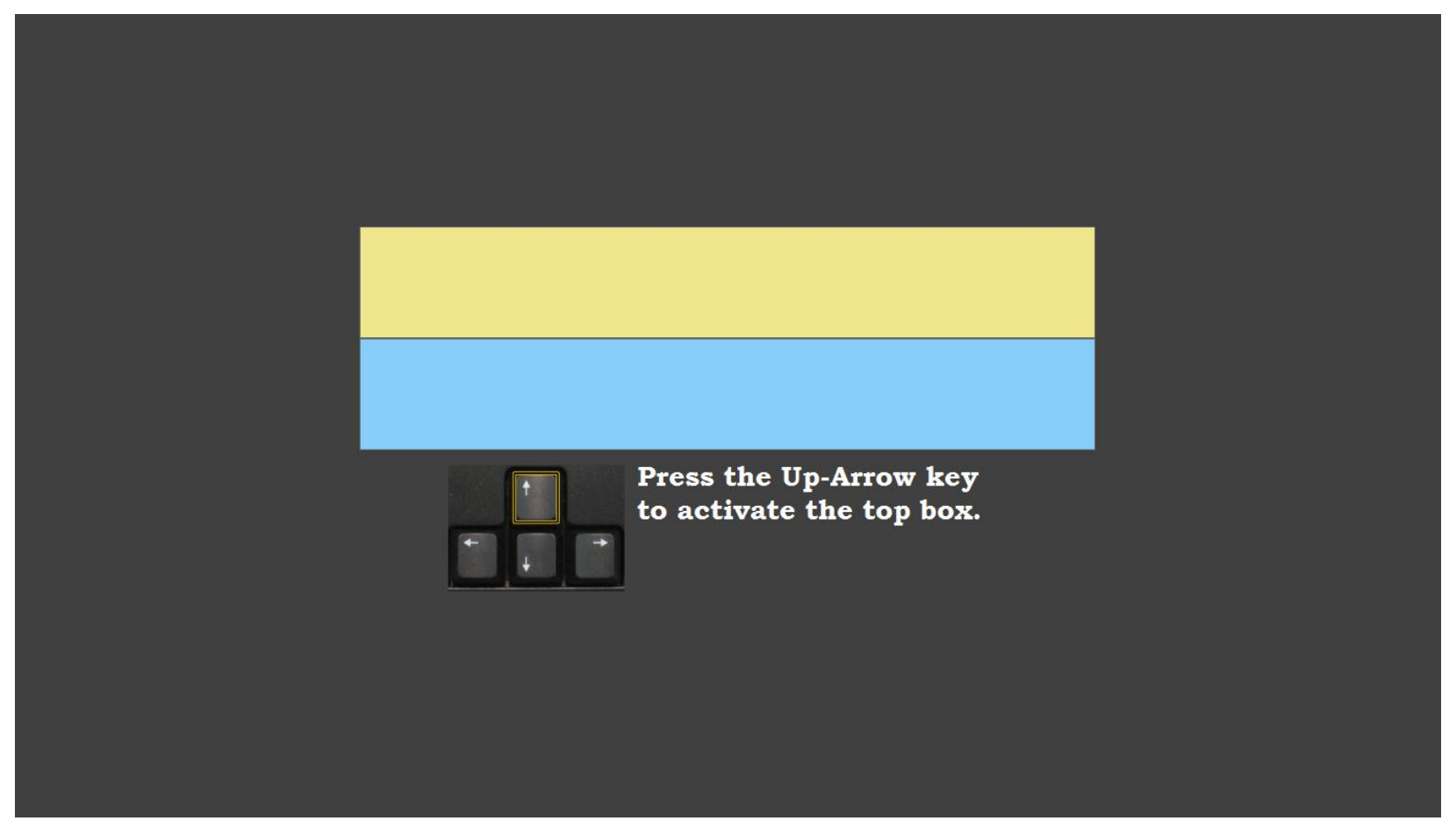

Figure 8. Screen display in Project 2, showing the initial screen. 


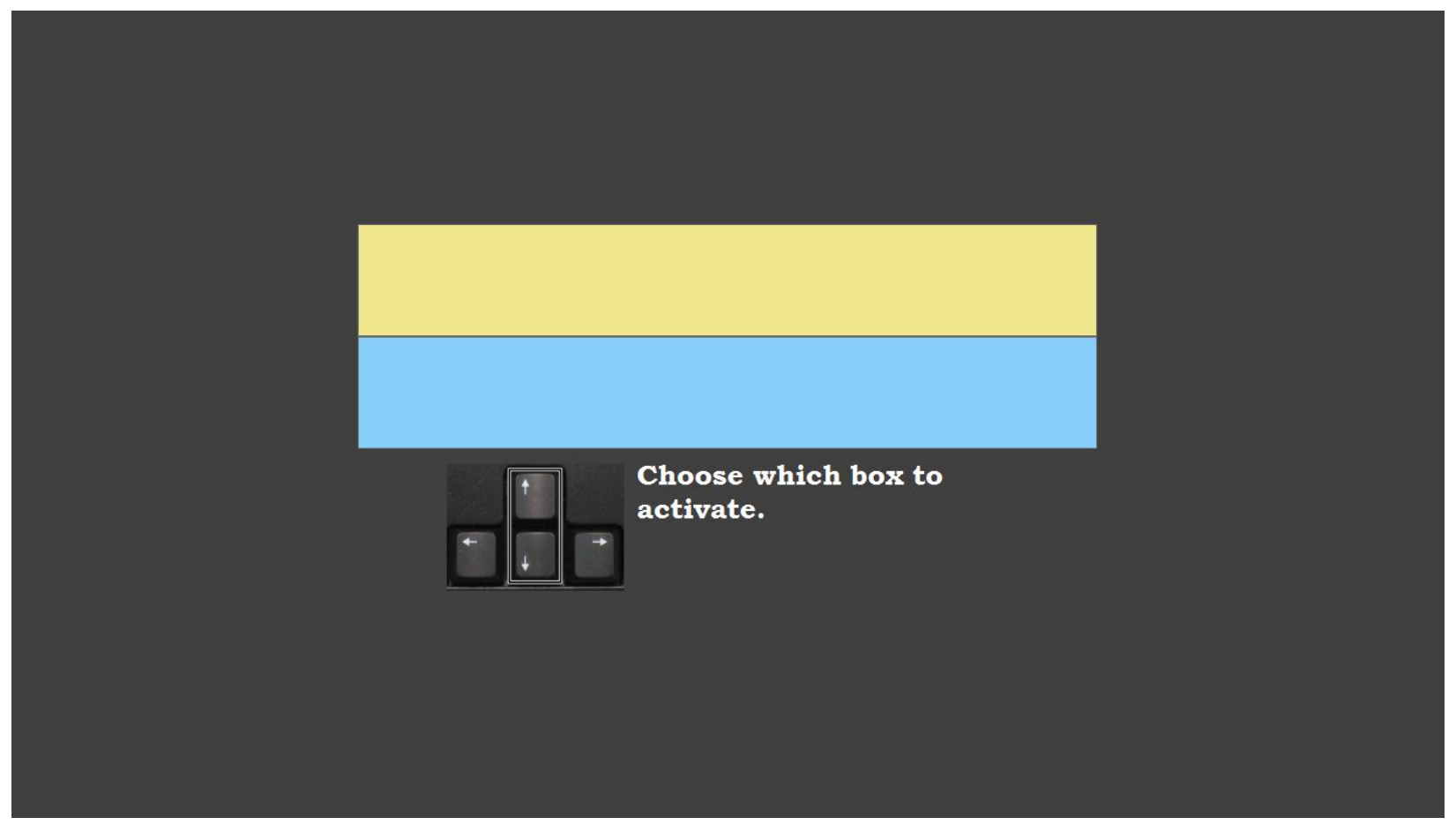

Figure 9. Screen display in Project 2, when a student could activate either the Alternate or the Imposed task by pressing the Up-arrow or Down-arrow key respectively. 




Figure 10. Mean post-reinforcement pause per session for Student 5 in Project 2. Sessions where a ratio run was never completed were excluded from the graph. 


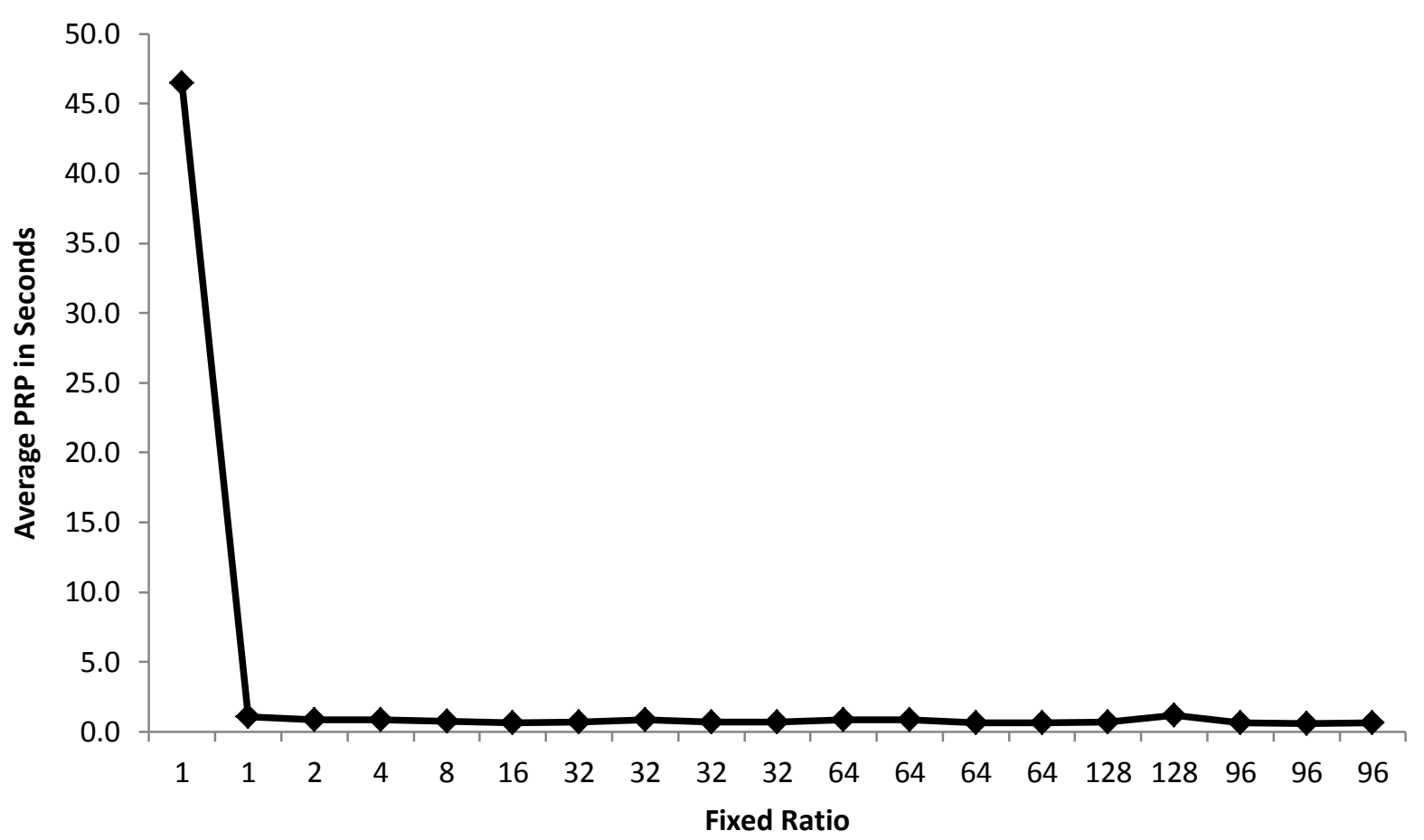

Figure 11. Mean post-reinforcement pause per session for Student 2 in Project 2. Sessions where a ratio run was never completed were excluded from the graph. 


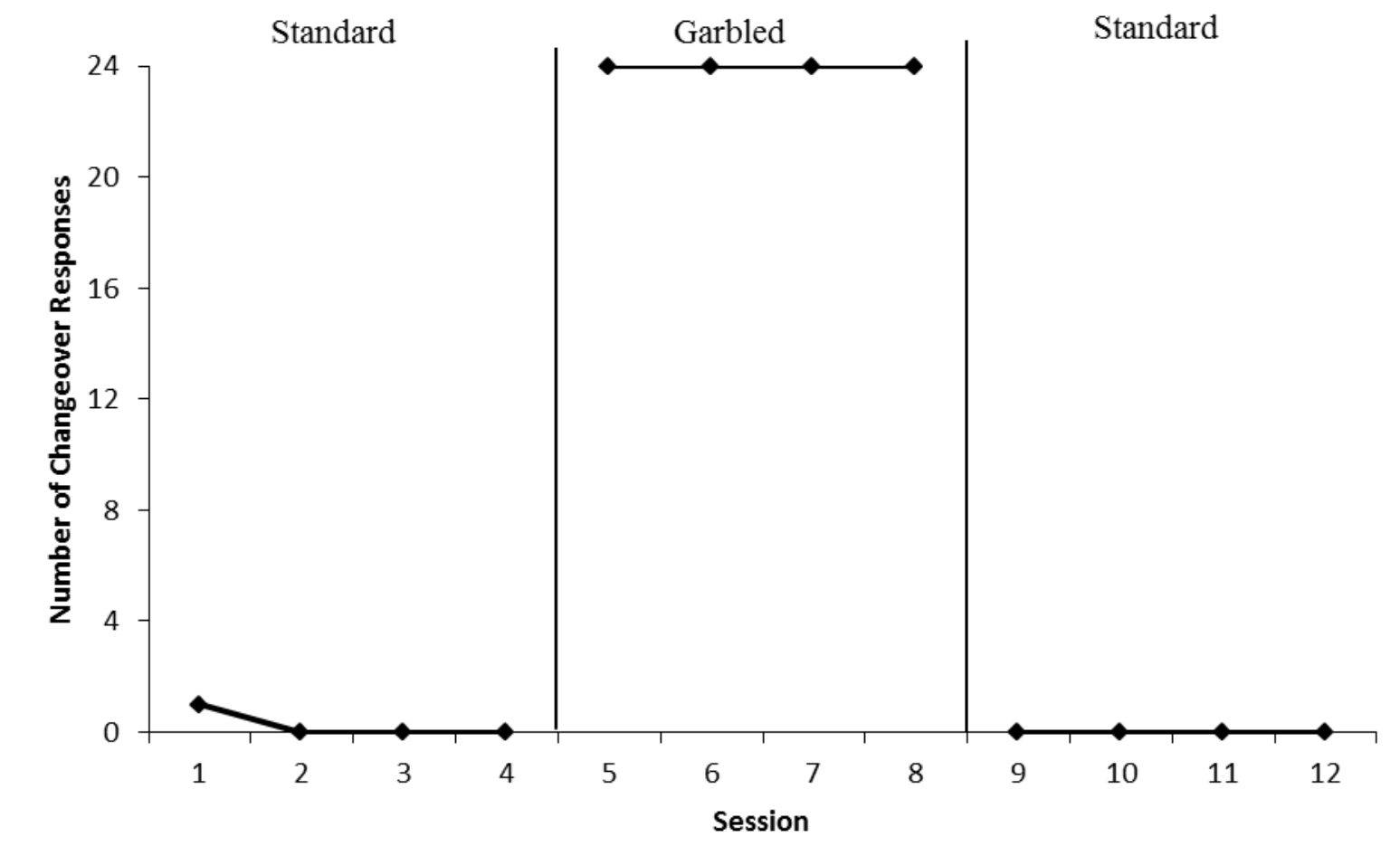

Figure 12. Number of changeover responses per session during the reversal phase of Project 2 for Student 4 . Phases are designated by type of transcription that served as the Imposed task. 


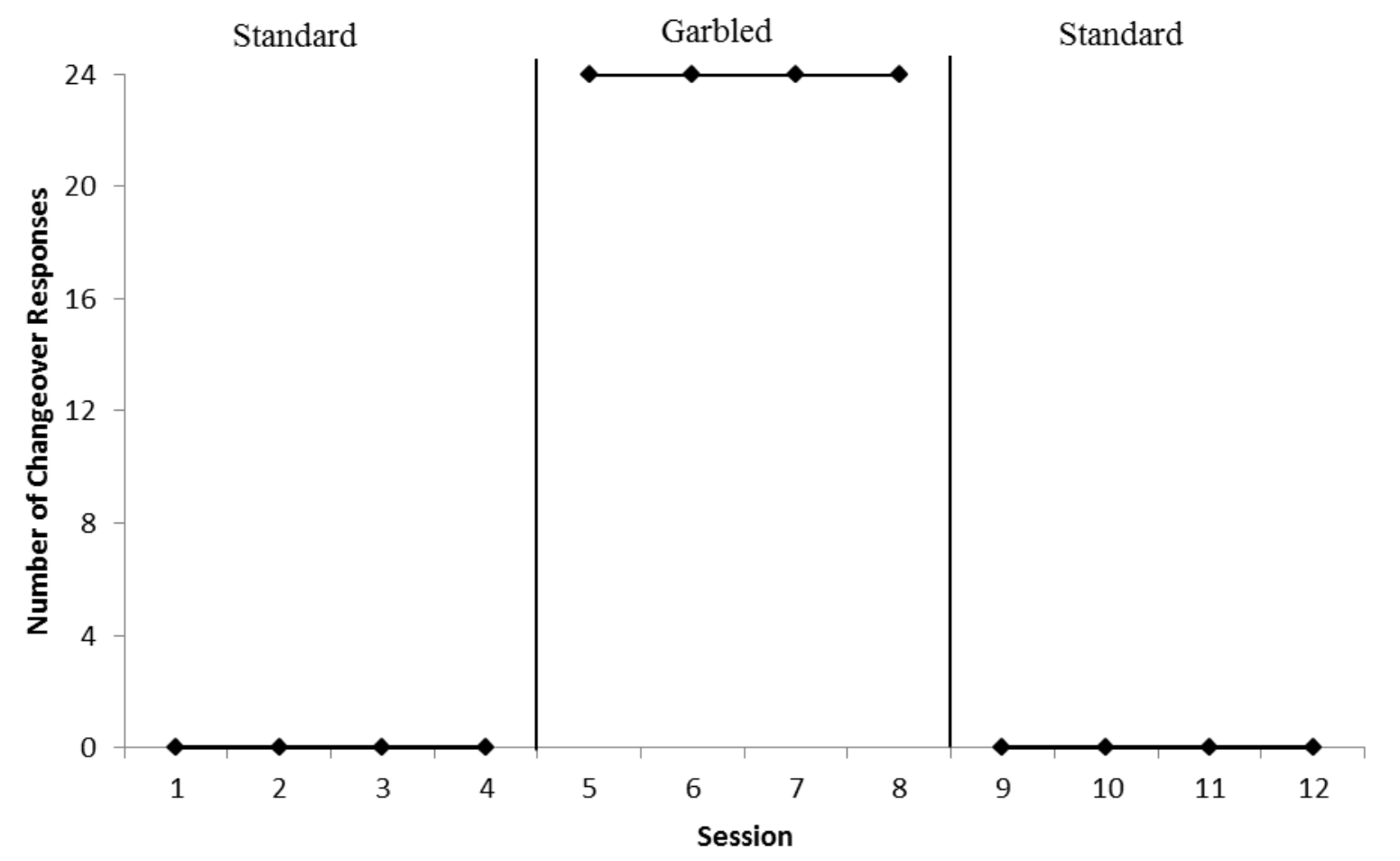

Figure 13. Number of changeover responses per session during the reversal phase of Project 2 for Student 5. Phases are designated by the type of transcription that served as the Imposed task. 